\title{
Características Físico-Químicas de Aguardente de Cana-de-Açúcar Submetida a Diferentes Condições de Envelhecimento
}

\author{
Letícia F. Viana, Marcio Caliari \& Manoel S. S. Junior
}

Durante doze meses, armazenou-se aguardente de cana-de-açúcar em barris da madeira sassafrás e galões de polipropileno e analisou-se, a cada mês, o teor de extrato seco, acidez, densidade e grau alcoólico. Pode-se concluir que para o extrato seco, acidez e densidade o tratamento com barril, cavacos e circulação forçada acelerou o processo em relação ao tratamento tradicional. Para o grau alcoólico, não ocorreu aceleração do processo em nenhum dos tratamentos. Para os galões de polipropileno, não ocorreu aumento que viabilizasse o uso no envelhecimento. Concluiu-se que a circulação e que os galões de polipropileno não são apropriados para esse fim.

Palavras chave: bebidas destiladas; análises laboratoriais; armazenamento.

During twelve months if stored brandy sugarcane in barrels of sassafras wood and gallons of polypropylene and analyzed every month dry matter content, acidity, density and alcoholic strength. It can be concluded that for the dry extract, acidity and density treatment barrel, chips and forced circulation accelerated the process compared to traditional treatment. For alcohol content was not speeding up the process in any of the treatments. For gallon polypropylene no increased, that make feasible the use in aging. It concluded that circulation and that gallon polypropylene are not suitable for this purpose.

Keywords: spirits; laboratory analysis; storage. 


\section{Introdução}

De acordo com a legislação vigente, aguardente de cana é a bebida com graduação alcoólica de $38 \%$ vol (trinta e oito por cento em volume) a $54 \%$ vol (cinquenta e quatro por cento em volume) a $20^{\circ} \mathrm{C}$ (vinte graus Celsius), obtida do destilado alcoólico simples de cana-de-açúcar ou pela destilação do mosto fermentado do caldo de cana-de-açúcar, podendo ser adicionada de açúcares até $6 \mathrm{~g} / \mathrm{l}$ (seis gramas por litro), expressos em sacarose. Cachaça é a denominação típica e exclusiva da aguardente de cana produzida no Brasil, com graduação alcoólica de $38 \%$ vol (trinta e oito por cento em volume) a $48 \%$ vol (quarenta e oito por cento em volume) a $20^{\circ} \mathrm{C}$ (vinte graus Celsius), obtida pela destilação do mosto fermentado do caldo de cana-de-açúcar com características sensoriais peculiares, podendo ser adicionada de açúcares até 6g/1 (seis gramas por litro), expressos em sacarose ${ }^{1}$.

Portanto, aguardente é uma bebida fermentada e destilada, sendo assim, após a obtenção do "vinho", uma mistura de água e álcool, durante o processo de fermentação, este passa para a etapa da destilação, a fim de atingir o grau alcoólico da bebida. Além da destilação, o envelhecimento e o engarrafamento são fatores importantes na qualidade da bebida, merecendo cuidados especiais, pois aumentam a qualidade físico-química e sensorial do produto, agregando valores de mercado ${ }^{2,3}$.

Conforme o Centro Brasileiro de Referência em Cachaça no ano de 2012, a aguardente/cachaça é o terceiro destilado mais consumido no mundo, ficando atrás apenas da vodca e saquê. A produção brasileira de cachaça anual gera em torno de 1 bilhão e 400 milhões de litros com 40. 000 produtores no Brasil. Desta produção, apenas $1 \%$ é exportado, sendo que $50 \%$ desta exportação acontece a granel, ou seja, com pouco ou nenhum valor agregado ao produto. Da produção total, $70 \%$ é feita de modo industrial, ou seja, em colunas de destilação e apenas 30\% produzida em alambiques de cobre ${ }^{4}$.

Ao longo dos anos, a cachaça não conheceu o problema de demanda de mercado, pois existiam poucos alambiques e a produção era suficiente. Todavia, com a abertura de mercado e a globalização, surgiram inúmeros micros, pequenos e médios produtores, fazendo com que a oferta aumentasse com a entrada de novas marcas de cachaça e aguardente (em torno de 4.000 marcas no Brasil), com preços mais acessíveis. Atualmente, os alambiques procuram otimizar o processo de produção, objetivando menor preço de mercado aliado à qualidade, pois este mercado, seja ele nacional ou internacional, é cada vez mais exigente. Neste contexto, é importante conhecer os fatores químicos e físicos que possam interferir na qualidade da bebida para atender aos consumidores mais exigentes ${ }^{3,4}$.

Sendo assim, o estudo do envelhecimento da aguardente de cana-de-açúcar é de suma importância, pois mesmo que a fermentação tenha sido a melhor possível e a destilação, a mais apurada, o produto final sempre terá sabor "ardente e seco". Quando a aguardente é armazenada em barris de madeira, adquire características da madeira, corrigindo assim defeitos da fermentação e da destilação, melhorando então o paladar da bebida ${ }^{5}$.

O objetivo com este trabalho foi investigar o efeito da madeira sassafrás sobre o processo de envelhecimento de aguardente de cana-de-açúcar em diferentes condições de envelhecimento, caracterizando a evolução do processo de envelhecimento, no período de 12 meses.

\section{Material e Métodos}

\section{MATERIAL}

Aguardente de cana-de-açúcar, não-envelhecida, proveniente da destilaria DECAL, localizada na cidade de Rio Verde, Goiás, Brasil.

\section{MÉTODOS}

\section{Protocolo experimental}

Utilizaram-se barris da madeira sassafrás e galões de polipropileno (PP) no processo de envelhecimento da aguardente de cana-de-açúcar. Os barris e os galões continham volume de vinte litros.

Foram avaliados dois experimentos distintos (um para a madeira e 1 para os galões de PP). No experimento 1 , utilizaram-se as seguintes condições de envelhecimento (tratamentos): $\mathrm{S}_{1}$ ) o envelhecimento tradicional, ou seja, sem circulação e sem cavacos, em barris de diferentes madeiras (sassafrás); $\mathrm{S}_{2}$ ) galões de $\mathrm{PP}$ com cavacos das diferentes madeiras; $S_{3}$ ) galões de PP com cavacos das diferentes madeiras e circulação forçada da aguardente de cana-de-açúcar mediante uma bomba submersa na bebida; $\mathrm{S}_{4}$ ) barris das diferentes madeiras com cavacos das respectivas madeiras e circulação forçada da aguardente de cana-de-açúcar mediante uma bomba submersa na bebida. 
No experimento, 2 utilizaram-se as seguintes condições (tratamentos): PPc) galões de PP com circulação forçada mediante uma bomba submersa na bebida; PP) galões de PP estático, ou seja, sem circulação e sem cavacos e 1 tratamento com a aguardente armazenada em galão de vidro estático, ou seja, sem circulação e sem cavacos (controle). Para comparação com os tratamentos, após doze meses de envelhecimento, utilizou-se uma amostra da aguardente de cana-de-açúcar recém destilada. Cada tratamento foi realizado com uma repetição. A introdução dos cavacos no interior dos vasilhames foi testada para verificar se ocorre uma intensificação da transferência de compostos da madeira para a bebida. Foram usados doze cavacos, correspondendo a aproximadamente $30 \mathrm{~g}$. A circulação forçada da bebida foi realizada mediante o uso de uma bomba submersa, modelo 160 V, marca Sarlo Better, de vazão constante, 1L/33s e contínua durante doze meses.

O experimento foi realizado nas dependências da Escola de Agronomia e Engenharia de Alimentos da Universidade Federal de Goiás, durante 12 meses, entre os meses de março de 2006 e fevereiro de 2007. Mensalmente, foram colhidas amostras para a realização de análises físico-químicas. Para comparar a aguardente de cana-de-açúcar em processo de envelhecimento com a aguardente de cana-de-açúcar não-envelhecida, também foram analisadas mensalmente amostras da aguardente de cana-de-açúcar, armazenada em garrafa de vidro. Após 12 meses de envelhecimento, foram realizadas análises sensoriais das amostras de cada experimento em diferentes madeiras, para avaliar a preferência dos consumidores em relação aos produtos obtidos em diferentes condições de envelhecimento.

Antes de iniciar o experimento, os barris foram tratados com água quente $\left(97^{\circ} \mathrm{C}\right)$ durante um mês. Diariamente trocavam-se as águas.

\section{Obtenção das amostras}

A aguardente de cana-de-açúcar utilizada nos experimentos foi coletada de um mesmo lote de produção, transportada ao Laboratório de Tecnologia de Vegetais da Escola de Agronomia e Engenharia de Alimentos da Universidade Federal de Goiás, distribuída e identificada nos tratamentos conforme explicitado na Tabela 1.

\section{Análises físico-químicas}

Para verificar as alterações no decorrer dos 12 meses de pesquisa, analisaram-se acidez volátil, densidade, grau alcoólico e extrato seco. Todas as análises foram realizadas em duplicata, conforme a metodologia de análises de bebidas e vinagres do Laboratório Nacional de Referência Vegetal do Ministério da Agricultura, Pecuária e Abastecimento ${ }^{6}$. Os resultados foram avaliados por meio de análise de regressão e as médias dos resultados foram preparadas através do teste de Tukey, utilizando-se os aplicativos EXCELL e SAS System.

Tabela 1. Designação e especificações dos experimentos e dos tratamentos de cada experimento

\begin{tabular}{|c|c|c|}
\hline Tratamento & Designação & Especificações \\
\hline Experimento 1 - S1 & $\begin{array}{l}\text { Sassafrás- } \\
\text { envelhecimento } \\
\text { tradicional }\end{array}$ & $\begin{array}{l}20 \text { litros de aguardente de cana-de-açúcar armazenados em barris de sassafrás durante } \\
\text { doze meses de envelhecimento. }\end{array}$ \\
\hline Experimento 2 - S2 & $\begin{array}{l}\text { PP - bomba/cavaco } \\
\text { Sassafrás }\end{array}$ & $\begin{array}{l}20 \text { litros de aguardente de cana-de-açúcar armazenados em galões de PP submetidos à } \\
\text { circulação forçada por bomba tipo diafragma contendo em torno de } 30 \mathrm{~g} \text { de cavacos da } \\
\text { madeira sassafrás durante doze meses de envelhecimento. }\end{array}$ \\
\hline Experimento 3 - S3 & PP - cavaco Sassafrás & $\begin{array}{l}20 \text { litros de aguardente de cana-de-açúcar armazenados em galões de PP contendo em } \\
\text { torno de } 20 \mathrm{~g} \text { da madeira sassafrás durante doze meses de envelhecimento. }\end{array}$ \\
\hline Experimento 4 - S4 & $\begin{array}{l}\text { Sassafrás - bomba/ } \\
\text { cavaco }\end{array}$ & $\begin{array}{l}20 \text { litros de aguardente de cana-de-açúcar armazenados em barris de sassafrás } \\
\text { submetidos à circulação forçada por bomba tipo diafragma, contendo em torno de } 30 \mathrm{~g} \\
\text { cavacos da mesma madeira durante doze meses de envelhecimento. }\end{array}$ \\
\hline Experimento 5 - PPc & $\mathrm{PP}-$ bomba & $\begin{array}{c}20 \text { litros de aguardente de cana-de-açúcar armazenados em galões de PP com } \\
\text { circulação forçada durante doze meses de envelhecimento. }\end{array}$ \\
\hline Experimento $6-\mathrm{PP}$ & $\begin{array}{l}\mathrm{PP}-\text { envelhecimento } \\
\text { tradicional }\end{array}$ & $\begin{array}{l}20 \text { litros de aguardente de cana-de-açúcar armazenados em galões de PP durante doze } \\
\text { meses de envelhecimento. }\end{array}$ \\
\hline Controle & Controle & $\begin{array}{c}20 \text { litros de aguardente de cana-de-açúcar armazenados em vidro durante doze meses } \\
\text { de envelhecimento. }\end{array}$ \\
\hline
\end{tabular}




\section{Resultados e Discussão}

Como pode ser observado na Tabela 2, a aguardente de cana-de-açúcar recém-destilada, utilizada na pesquisa, atendeu aos padrões legais vigentes, estabelecidos pela Portaria do MAPA n ${ }^{\circ} 13$ de $2005^{1}$.

Tabela 2. Caracterização da aguardente de cana-de-açúcar inicial utilizada nos experimentos.

\begin{tabular}{|c|c|c|}
\hline Determinações & Padrão legal1 & $\begin{array}{c}\text { Aguardente de } \\
\text { cana-de-açúcar } \\
\text { recém-destilada }\end{array}$ \\
\hline $\begin{array}{c}\text { Grau alcoólico } \\
\text { (\%vol) }\end{array}$ & 38,00 a 54,00 & $45,10 \pm 0,70$ \\
\hline Extrato seco (g/L) & --------- & $0,05 \pm 0,02$ \\
\hline $\begin{array}{c}\text { Acidez volátil } \\
\text { em ácido acético } \\
(\mathrm{mg} / 100 \mathrm{~mL} \text { etanol) }\end{array}$ & $\leq 150,00$ & $11,10 \pm 3,34$ \\
\hline $\begin{array}{c}\text { Álcoois superiores } \\
(\mathrm{mg} / 100 \mathrm{~mL} \text { etanol) }\end{array}$ & $\leq 360,00$ & $327,74 \pm 0,00$ \\
\hline $\begin{array}{c}\text { Ésteres em acetato } \\
\text { de etila (mg/100mL } \\
\text { etanol) }\end{array}$ & $\leq 200,00$ & $13,86 \pm 0,00$ \\
\hline $\begin{array}{c}\text { Álcool metílico } \\
(\mathrm{mg} / 100 \mathrm{~mL} \text { etanol) }\end{array}$ & $\leq 50,00$ & $4,33 \pm 0,00$ \\
\hline Densidade (g/mL) & ---------- & $0,86 \pm 0,04$ \\
\hline
\end{tabular}

Estudos realizados por Furtado, sobre a avaliação sensorial descritiva de aguardente de cana-de-açúcar: influência da composição em suas características sensoriais e correlação entre as medidas sensoriais e físico-químicas, analisa sete amostras de aguardente de cana-de-açúcar recém-destiladas e quatro aguardentes de cana-de-açúcar de cana comerciais e avalia o grau alcoólico das amostras recém-destiladas quanto para as comerciais encontraram grau alcoólico de 42 e $43^{\circ} \mathrm{C}$, resultados estes compatíveis com o do trabalho em estudo ${ }^{7}$.

Nas Figuras 1 e 2, encontram-se as fotos das aguardentes de cana-de-açúcar envelhecidas com uso de sassafrás no processo tradicional $\left(\mathrm{S}_{1}\right)$, em galões de polipropileno com cavacos de sassafrás e circulação forçada $\left(\mathrm{S}_{2}\right)$, em galões de polipropileno com cavacos de sassafrás $\left(\mathrm{S}_{3}\right)$ e em barril de sassafrás com cavacos de sassafrás e circulação forçada $\left(\mathrm{S}_{4}\right)$.
O aspecto visual nas Figuras 1 e 2 indicaram uma crescente evolução para a cor vermelho escuro, nos tratamentos $\mathrm{S}_{1}$ e $\mathrm{S}_{4}$, principalmente no tratamento $\mathrm{S} 4$, que utilizou barril de sassafrás e cavacos de sassafrás durante o envelhecimento. Nos tratamentos $\mathrm{S}_{2}$ e $\mathrm{S}_{3}$, a evolução visual da cor tendeu para o amarelo tendo tonalidade mais intensa nos tratamento $\mathrm{S}_{2}$.

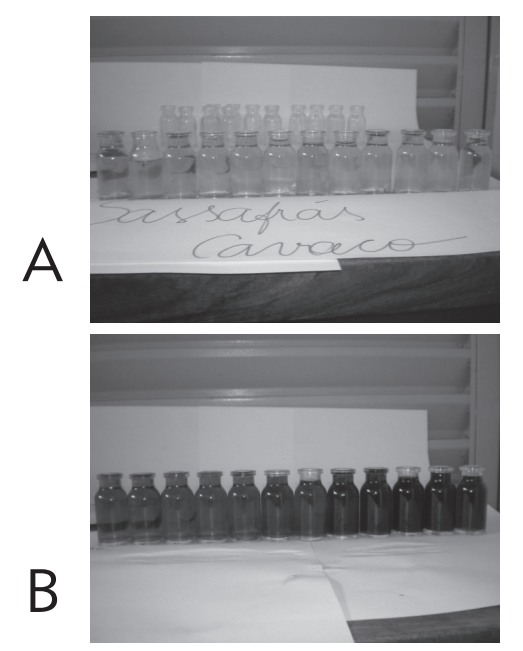

Figura 1. (A) Evolução mensal do aspecto visual da aguardente de cana-de-açúcar envelhecida da forma tradicional em barril de sassafrás (tratamento S1). (B) Evolução mensal do aspecto visual da aguardente de cana-de-açúcar envelhecida em galões de polipropileno com cavacos de sassafrás e circulação forçada (tratamento S2).

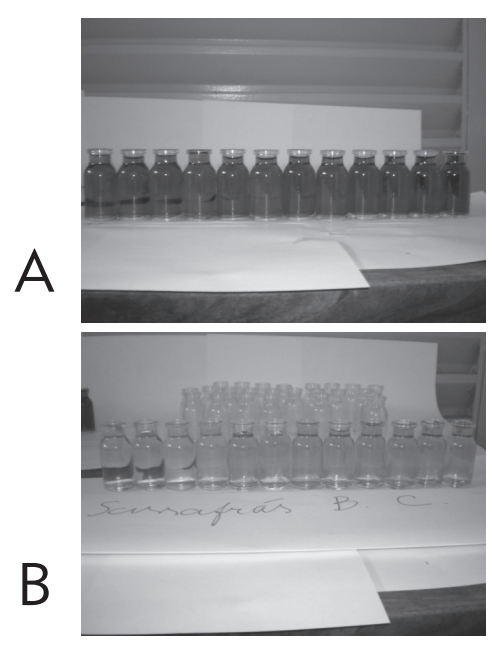

Figura 2. (A) Evolução mensal do aspecto visual da aguardente de cana-de-açúcar envelhecida em galões de polipropileno com cavacos de sassafrás (tratamento S3). (B) Evolução mensal do aspecto visual da aguardente de cana-de-açúcar envelhecida em barril com cavacos de sassafrás com circulação forçada (tratamento S4). 


\section{EVOLUÇÃO DO TEOR DE EXTRATO SECO}

Na Tabela 3, estão apresentados os resultados médios mensais do teor de extrato seco, os desvios-padrão e os coeficientes de variação das aguardentes de cana-deaçúcar envelhecidas sob diferentes condições com o uso de sassafrás no período de doze meses.

Tabela 3. Teores médios mensais, desvio padrão e coeficiente de variação do teor de extrato seco $(\mathrm{g} / \mathrm{L})$ obtidos nos diferentes tratamentos, utilizando sassafrás durante o período de doze meses de envelhecimento.

\begin{tabular}{|c|c|c|c|c|c|}
\hline \multirow{2}{*}{ Mês } & \multicolumn{5}{|c|}{ Tratamentos } \\
\hline & S1 & S2 & S3 & S4 & C.V. $(\%)^{*}$ \\
\hline 1 & $\begin{array}{c}0,81 \mathrm{~b} \pm \\
0,04\end{array}$ & $\begin{array}{c}0,22 \mathrm{c} \pm \\
0,01\end{array}$ & $\begin{array}{c}0,09 \mathrm{~d} \pm \\
0,06\end{array}$ & $\begin{array}{c}0,96 a \pm \\
0,05\end{array}$ & 6,62 \\
\hline 2 & $\begin{array}{c}0,93 \mathrm{~b} \pm \\
0,03\end{array}$ & $\begin{array}{c}0,24 \mathrm{c} \pm \\
0,03\end{array}$ & $\begin{array}{c}0,12 \mathrm{~d} \pm \\
0,01\end{array}$ & $\begin{array}{c}1,35 \mathrm{a} \pm \\
0,02\end{array}$ & 3,14 \\
\hline 3 & $\begin{array}{c}1,06 \mathrm{~b} \pm \\
0,04\end{array}$ & $\begin{array}{c}0,25 \mathrm{c} \pm \\
0,02\end{array}$ & $\begin{array}{c}0,15 \mathrm{c} \pm \\
0,01\end{array}$ & $\begin{array}{c}1,80 \mathrm{a} \pm \\
0,24\end{array}$ & 13,97 \\
\hline 4 & $\begin{array}{c}1,15 b \pm \\
0,01\end{array}$ & $\begin{array}{c}0,26 \mathrm{c} \pm \\
0,01\end{array}$ & $\begin{array}{c}0,17 \mathrm{c} \pm \\
0,00\end{array}$ & $\begin{array}{c}2,24 \mathrm{a} \pm \\
0,13\end{array}$ & 6,14 \\
\hline 5 & $\begin{array}{c}1,22 b \pm \\
0,04\end{array}$ & $\begin{array}{c}0,34 \mathrm{c} \pm \\
0,05\end{array}$ & $\begin{array}{c}0,19 \mathrm{c} \pm \\
0,00\end{array}$ & $\begin{array}{c}2,61 \mathrm{a} \pm \\
0,15\end{array}$ & 6,69 \\
\hline 6 & $\begin{array}{c}1,33 b \pm \\
0,05\end{array}$ & $\begin{array}{c}0,28 \mathrm{c} \pm \\
0,07\end{array}$ & $\begin{array}{c}0,20 \mathrm{c} \pm \\
0,00\end{array}$ & $\begin{array}{c}2,95 \mathrm{a} \pm \\
0,05\end{array}$ & 7,17 \\
\hline 7 & $\begin{array}{c}1,49 b \pm \\
0,04\end{array}$ & $\begin{array}{c}0,08 \mathrm{~d} \pm \\
0,02\end{array}$ & $\begin{array}{c}0,24 \mathrm{c} \pm \\
0,01\end{array}$ & $\begin{array}{c}3,42 \mathrm{a} \pm \\
0,12\end{array}$ & 3,90 \\
\hline 8 & $\begin{array}{c}1,70 b \pm \\
0,12\end{array}$ & $\begin{array}{c}0,13 \mathrm{c} \pm \\
0,03\end{array}$ & $\begin{array}{c}0,24 \mathrm{c} \pm \\
0,00\end{array}$ & $\begin{array}{c}4,23 \mathrm{a} \pm \\
0,34\end{array}$ & 10,89 \\
\hline 9 & $\begin{array}{c}1,98 \mathrm{~b} \pm \\
0,11\end{array}$ & $\begin{array}{c}0,13 \mathrm{~d} \pm \\
0,00\end{array}$ & $\begin{array}{c}0,29 \mathrm{c} \pm \\
0,00\end{array}$ & $\begin{array}{c}4,63 a \pm \\
0,05\end{array}$ & 3,79 \\
\hline 10 & $\begin{array}{c}2,22 b \pm \\
0,03\end{array}$ & $\begin{array}{c}0,17 \mathrm{~d} \pm \\
0,02\end{array}$ & $\begin{array}{c}0,35 \mathrm{c} \pm \\
0,01\end{array}$ & $\begin{array}{c}4,95 \mathrm{a} \pm \\
0,12\end{array}$ & 2,59 \\
\hline 11 & $\begin{array}{c}2,65 b \pm \\
0,23\end{array}$ & $\begin{array}{c}0,22 \mathrm{c} \pm \\
0,03\end{array}$ & $\begin{array}{c}0,46 \mathrm{c} \pm \\
0,03\end{array}$ & $\begin{array}{c}5,91 \mathrm{a} \pm \\
0,16\end{array}$ & 5,31 \\
\hline 12 & $\begin{array}{c}2,52 b \pm \\
0,94\end{array}$ & $\begin{array}{c}0,25 \mathrm{c} \pm \\
0,02\end{array}$ & $\begin{array}{c}0,64 \mathrm{c} \pm \\
0,02\end{array}$ & $\begin{array}{c}6,40 \mathrm{a} \pm \\
0,15\end{array}$ & 19,56 \\
\hline
\end{tabular}

*coeficiente variação; a,b letras iguais nas linhas significam que os tratamentos não diferiram entre si $(p>0,05)$, pelo teste de Tukey. S1 a $S 4=$ tratamentos 1 a 4 com madeira sassafrás; Tratamento 1 - envelhecimento tradicional; Tratamento 2 - galóes de polipropileno com cavacos e circulação forçada; Tratamento 3 galôes de polipropileno com cavacos e tratamento 4 - barril de madeira com cavacos e circulação forçada.

Os tratamentos $\mathrm{S}_{1}$ e $\mathrm{S}_{4}$ foram diferentes significativamente em todos os meses e também foram diferentes significativamente em todo o período de experimento dos tratamentos $\mathrm{S}_{2}$ e $\mathrm{S}_{3}$.
O teor de extrato seco não possui padrão na legislação, entretanto são os extratos que ajudam na mudança da cor das bebidas destiladas consideradas envelhecidas, sendo assim, é ideal que haja um mínimo de transferência de extratos para a bebida durante este processo. Pode-se verificar pela Tabela 3 que as bebidas envelhecidas em galões de polipropileno $\left(\mathrm{S}_{2}\right.$ e $\left.\mathrm{S}_{3}\right)$ durante os doze meses de estudo não apresentaram teor de extrato seco igual ao mínimo obtido pela bebida no envelhecimento tradicional (S1), sendo possivelmente por este motivo a diferença de cor observada entre as bebidas nas Figuras 1 e 2.

Na Tabela 4, estão descritas as equações de regressão, os valores dos coeficientes de determinação (R2), coeficientes de variações (C.V.) e o nível de significância da regressão (p), para os quatro tratamentos que utilizaram a madeira sassafrás. Na Figura 3, encontramse os respectivos gráficos da evolução mensal do extrato seco, para os tratamentos utilizando sassafrás.

Tabela 4. Equações de regressão, coeficientes de determinação, coeficientes de variação e nível de significância do modelo para extrato seco $(\mathrm{g} / \mathrm{L})$, das aguardentes de cana-de-açúcar envelhecidas sob diferentes tratamentos utilizando sassafrás durante doze meses.

\begin{tabular}{|c|c|c|c|c|}
\hline Tratamento $^{4}$ & Equação & R2(1) & C.V.2 & p3 \\
\hline S1 & $\begin{array}{c}\mathrm{y}=0,7466 \\
\mathrm{e} 0,1052 \mathrm{x}\end{array}$ & 0,9045 & 18,22 & $<0,001^{* *}$ \\
\hline $\mathrm{S} 2$ & $\begin{array}{c}\mathrm{y}=0,0937 \\
\mathrm{e} 0,1156 \mathrm{x}\end{array}$ & 0,756 & 17,11 & $<0,001^{* *}$ \\
\hline $\mathrm{S} 3$ & $\begin{array}{c}\mathrm{y}=0,0865 \\
\mathrm{e} 0,1544 \mathrm{x}\end{array}$ & 0,9673 & 21,94 & $0,77 \mathrm{~ns}$ \\
\hline $\mathrm{S} 4$ & $\begin{array}{c}\mathrm{y}=1,0326 \\
\mathrm{e} 0,1632 \mathrm{x}\end{array}$ & 0,9579 & 6,67 & $0,005^{*}$ \\
\hline
\end{tabular}

1 - Coeficiente de determinação; 2 - coeficiente de variação, 3 - nível de significância da equação 4 - Tratamento S1 - tradicional em sassafrás, Tratamento S2 - galões de polipropileno com cavacos de sassafrás e circulação forçada, Tratamento S3 - galões de polipropileno com cavacos de sassafrás, Tratamento S4 - barril de sassafrás com cavacos de sassafrás e circulação forçada, onde y é igual ao teor de extrato seco $(\mathrm{g} / \mathrm{L})$ e x é igual ao tempo em (meses).

Em todos os tratamentos, nos quais se utilizou a madeira sassafrás, observou-se um aumento do teor de extrato seco obedecendo a uma equação exponencial. Os valores de R2 encontrados nestes tratamentos variaram entre 0,7560 a 0,9673 . Neste experimento, o tratamento S1 e S2 obtiveram coeficientes de variação médios, o tratamento S4 obteve coeficiente de variação baixo e o tratamento $\mathrm{S} 3$ obteve coeficiente de variação alto. 

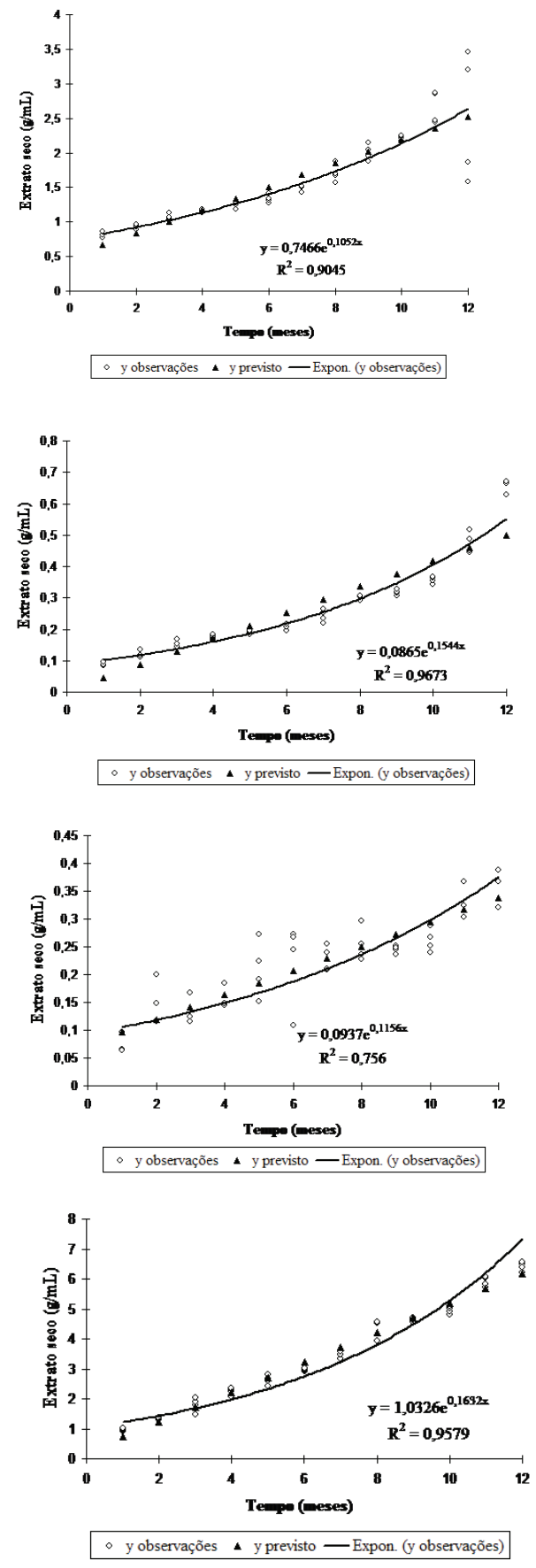

Figura 3. Evolução mensal no teor de extrato seco das aguardentes de cana-de-açúcar envelhecidas sob os tratamentos S1 (tradicional sassafrás), S3 (galões de polipropileno com cavacos de sassafrás), S2 (galões de polipropileno com cavacos de sassafrás e circulação forçada) e S4 (barril de sassafrás com cavacos de sassafrás e circulação forçada), respectivamente em linhas.
Em estudos sobre a maturação de aguardente de canade-açúcar, composta com extrato de madeira de carvalho em embalagens polietileno tereftalato (PET), avaliou-se o teor de extrato seco no destilado alcoólico simples de canade-açúcar (dasca) bidestilado utilizado para maceração da madeira de carvalho, sendo que foram realizadas treze macerações consecutivas, em batelada, mantendo a mesma quantidade de madeira. Após a maceração, drenava-se por gravidade a fase sólida e filtrava-se a fase líquida para retirada de extratos específicos para análise. Os extratos de carvalho eram armazenados nos períodos sem dasca em condições herméticas, à temperatura ambiente até a nova batelada. Cada batelada usava uma nova dasca. O autor verificou que, conforme realizava as extrações, o teor de extrato seco foi diminuindo, ou seja, foi retirado da madeira todo o extrato que era transferido para a bebida a cada batelada de maceração. $\mathrm{O}$ extrato que começou com 8,799 $\mathrm{g} / \mathrm{L}$ no final das treze bateladas estava com $0,462 \mathrm{~g} / \mathrm{L}^{8}$.

Autores estudaram o envelhecimento da aguardente de cana-de-açúcar com circulação forçada e o efeito da presença de ar no sistema. Durante 180 dias, foram utilizados dois ancorotes de carvalho de 5 litros para processo tradicional, seis ancorotes de cinco litros com circulação forçada. Verificouse que, conforme passavam os meses, o teor de extrato seco aumentou tanto no envelhecimento tradicional como no envelhecimento com circulação forçada. E concluiu-se que a presença de ar no sistema aumentou o teor de extrato seco na bebida?.

A Figura 3 apresenta a evolução do teor de extrato seco no decorrer do período de armazenamento. $\mathrm{Na}$ Figura 3, pode-se observar que a madeira sassafrás liberou seu extrato em todos os tratamentos durante todo o período de envelhecimento. No entanto, no tratamento $\mathrm{S}_{2}$, a incorporação de extrato foi menor que o tratamento tradicional $\left(\mathrm{S}_{1}\right)$. A incorporação não atingiu os níveis do primeiro mês de envelhecimento tradicional $\left(\mathrm{S}_{1}\right)$. No tratamento $\mathrm{S}_{3}$, a incorporação ao final do envelhecimento atingiu os níveis do primeiro mês no sistema tradicional. Quanto à circulação, pode-se verificar nos tratamentos $\mathrm{S}_{2}$ e $\mathrm{S}_{3}$ a pequena influência desta nos tratamentos. Já no tratamento $\mathrm{S}_{4}$, observa-se que com apenas seis meses de envelhecimento, atingiu níveis de transferência de extrato seco similar ao do tratamento tradicional $\left(\mathrm{S}_{1}\right)$, com doze meses. Sabendo-se da pequena influência da circulação, pode-se dizer que o grande aumento do teor de extrato seco 
do tratamento $\mathrm{S}_{4}$ está relacionado ao aumento de área da madeira exposto à ação da bebida.

\section{EVOLUÇÃO DA ACIDEZ VOLÁTIL}

$\mathrm{Na}$ Tabela 5, estão apresentados os resultados médios mensais da acidez volátil, os desvios-padrão e os coeficientes de variação das aguardentes de cana-deaçúcar envelhecidas sob diferentes condições no período de doze meses.

Tabela 5. Teores médios mensais, desvio padrão e coeficiente de variação da acidez volátil $(\mathrm{mg} / 100 \mathrm{~mL}$ etanol) obtidos nos diferentes tratamentos, utilizando sassafrás durante o período de doze meses de envelhecimento.

\begin{tabular}{|c|c|c|c|c|c|}
\hline \multirow{2}{*}{ Mês } & \multicolumn{5}{|c|}{ Tratamentos } \\
\hline & S1 & $\mathrm{S} 2$ & S3 & S4 & C.V. $(\%)^{*}$ \\
\hline 1 & $\begin{array}{l}21,00 \mathrm{~b} \\
\pm 7,35\end{array}$ & $\begin{array}{c}15,86 b, c \\
\pm 2,89\end{array}$ & $\begin{array}{c}13,37 \mathrm{c} \pm \\
0,15\end{array}$ & $\begin{array}{l}40,63 \mathrm{a} \\
\pm 0,14\end{array}$ & 15,06 \\
\hline 2 & $\begin{array}{l}31,44 b \\
\pm 2,80\end{array}$ & $\begin{array}{l}19,47 \mathrm{c} \\
\pm 0,56\end{array}$ & $\begin{array}{c}16,70 \mathrm{c} \pm \\
3,70\end{array}$ & $\begin{array}{l}42,73 \mathrm{a} \\
\pm 1,31\end{array}$ & 5,95 \\
\hline 3 & $\begin{array}{c}37,02 \mathrm{~b} \\
\pm 3,11\end{array}$ & $\begin{array}{l}21,64 \mathrm{c} \\
\pm 0,25\end{array}$ & $\begin{array}{c}20,21 \mathrm{c} \pm \\
0,44\end{array}$ & $\begin{array}{l}45,45 \mathrm{a} \\
\pm 1,10\end{array}$ & 5,64 \\
\hline 4 & $\begin{array}{l}41,81 \mathrm{~b} \\
\pm 0,91\end{array}$ & $\begin{array}{l}21,39 \mathrm{c} \\
\pm 0,47\end{array}$ & $\begin{array}{c}22,37 \mathrm{c} \pm \\
0,04\end{array}$ & $\begin{array}{l}51,96 \mathrm{a} \\
\pm 4,80\end{array}$ & 6,45 \\
\hline 5 & $\begin{array}{l}43,65 b \\
\pm 1,58\end{array}$ & $\begin{array}{l}22,28 \mathrm{c} \\
\pm 0,22\end{array}$ & $\begin{array}{c}23,03 \mathrm{c} \pm \\
0,27\end{array}$ & $\begin{array}{l}58,14 a \\
\pm 1,91\end{array}$ & 2,72 \\
\hline 6 & $\begin{array}{l}47,52 b \\
\pm 0,64\end{array}$ & $\begin{array}{l}23,45 \mathrm{c} \\
\pm 0,15\end{array}$ & $\begin{array}{c}24,05 \mathrm{c} \pm \\
0,30\end{array}$ & $\begin{array}{l}64,37 \mathrm{a} \\
\pm 1,92\end{array}$ & 2,08 \\
\hline 7 & $\begin{array}{l}49,27 \mathrm{~b} \\
\pm 1,12\end{array}$ & $\begin{array}{l}24,75 \mathrm{~d} \\
\pm 0,81\end{array}$ & $\begin{array}{c}25,54 \mathrm{c} \pm \\
0,66\end{array}$ & $\begin{array}{l}73,09 a \\
\pm 4,40\end{array}$ & 4,28 \\
\hline 8 & $\begin{array}{l}54,36 \mathrm{~b} \\
\pm 2,60\end{array}$ & $\begin{array}{l}27,14 \mathrm{c} \\
\pm 0,93\end{array}$ & $\begin{array}{c}26,23 \mathrm{c} \pm \\
0,10\end{array}$ & $\begin{array}{c}77,46 a \\
\pm 1,66\end{array}$ & 4,08 \\
\hline 9 & $\begin{array}{l}58,43 b \\
\pm 1,17\end{array}$ & $\begin{array}{l}29,25 \mathrm{c} \\
\pm 0,78\end{array}$ & $\begin{array}{l}27,03 \mathrm{~d} \\
\pm 0,51\end{array}$ & $\begin{array}{l}82,35 \mathrm{a} \\
\pm 1,17\end{array}$ & 0,87 \\
\hline 10 & $\begin{array}{l}60,89 \mathrm{~b} \\
\pm 0,52\end{array}$ & $\begin{array}{l}30,60 \mathrm{~d} \\
\pm 0,21\end{array}$ & $\begin{array}{c}29,77 \mathrm{c} \pm \\
1,96\end{array}$ & $\begin{array}{l}86,57 \mathrm{a} \\
\pm 2,37\end{array}$ & 2,10 \\
\hline 11 & $\begin{array}{l}63,52 b \\
\pm 1,54\end{array}$ & $\begin{array}{l}38,47 \mathrm{c} \\
\pm 8,05\end{array}$ & $\begin{array}{c}33,82 \mathrm{c} \pm \\
0,76\end{array}$ & $\begin{array}{l}102,00 \mathrm{a} \\
\pm 10,70\end{array}$ & 8,27 \\
\hline 12 & $\begin{array}{l}68,03 \mathrm{~b} \\
\pm 1,49\end{array}$ & $\begin{array}{l}60,25 \mathrm{c} \\
\pm 0,79\end{array}$ & $\begin{array}{c}36,74 \mathrm{c} \pm \\
2,39\end{array}$ & $\begin{array}{l}136,24 a \\
\pm 18,57\end{array}$ & 11,45 \\
\hline
\end{tabular}

*coeficiente variação; a,b letras iguais nas linhas significam que os tratamentos não diferiram entre si $(p>0,05)$, pelo teste de Tukey. S1 a $S 4=$ tratamentos 1 a 4 com madeira sassafrás; Tratamento 1 - envelhecimento tradicional; Tratamento 2 - galóes de polipropileno com cavacos e circulação forçada: Tratamento 3 galões de polipropileno com cavacos e tratamento 4 - barril de madeira com cavacos e circulação forçada.
Os tratamentos $\mathrm{S}_{1}$ e $\mathrm{S}_{4}$ diferiram entre si em todo o período do estudo e diferiram também dos tratamentos $S_{2}$ e $S_{3}$, que não diferiram entre si em praticamente todos os meses. De acordo com a legislação, todos os tratamentos encontram-se dentro dos padrões legais vigentes.

Foi estudado o efeito da presença de ar no envelhecimento de doze amostras envelhecidas de aguardente de cana-de-açúcar com circulação forçada, durante 180 dias, em ancorotes de carvalho de 5 litros, sendo seis amostras envelhecidas no processo tradicional e seis pelo processo de circulação forçada. Verificou-se que ao longo do envelhecimento houve um aumento da acidez volátil na aguardente de cana-de-açúcar, conforme era esperado. Observou-se também que a presença de ar no sistema de circulação forçada certamente favoreceu o processo de envelhecimento, pois ocorreu uma maior extração dos componentes da madeira ${ }^{10}$. Também foi investigado o envelhecimento da aguardente de cana-deaçúcar em um estudo comparativo entre o envelhecimento tradicional em carvalho (Quercus sp) utilizando cinco tipos de amostras de aguardente de cana-de-açúcar, obtida por destilação contínua. Os resultados mostraram, após seis meses de envelhecimento, uma diminuição da acidez volátil, que explicou por meio de evaporação do ácido acético pelos poros da madeira ou durante o processo de aeração ${ }^{11}$.

Na Tabela 6, estão descritas as equações de regressão, os valores dos coeficientes de determinação $\left(\mathrm{R}^{2}\right)$ e os coeficientes de variações (C.V.) e o nível de significância da regressão (p), nos quatro tratamentos que utilizaram a madeira sassafrás, para a acidez volátil.

Nos tratamentos $\mathrm{S}^{1}$ a $\mathrm{S}^{4}$, em que se utilizaram os barris de sassafrás, obtiveram-se coeficientes de variação variando de 7,12 a 24,24 sendo que o tratamento $S^{2}$ obteve o maior coeficiente de variação.

$\mathrm{Na}$ Figura 4, encontram-se os respectivos gráficos da evolução mensal da acidez volátil para os tratamentos utilizando sassafrás.

Os tratamentos $\mathrm{S}^{2}$ (cavacos e circulação) e $\mathrm{S}^{3}$ (cavacos), não tiveram muito aumento da acidez volátil na bebida, visto que não estavam nos barris e sim em embalagens polipropileno. O aumento da acidez volátil foi muito pequeno não podendo ser utilizado para envelhecimento, visto que, durante doze meses de envelhecimento, o aumento conseguiu alcançar os níveis do primeiro 
Tabela 6. Equações de regressão, coeficientes de determinação, coeficientes de variação e nível de significância do modelo para acidez volátil (mg/100mL etanol), das aguardentes de cana-de-açúcar envelhecidas sob diferentes tratamentos utilizando sassafrás durante doze meses.

\begin{tabular}{|c|c|c|c|c|}
\hline Tratamento $^{4}$ & Equação & R2(1) & C.V.2 & p3 \\
\hline & $\mathrm{y}=19,2730$ & & & \\
& $+5,621 \mathrm{x}$ & 0,9502 & 7,12 & $<0,001^{* *}$ \\
& $-0,1411 \mathrm{x} 2$ & & & \\
\hline & $\mathrm{y}=22,784$ & & & \\
S2 & $-2,7821 \mathrm{x}$ & 0,8261 & 24,24 & $<0,001^{* *}$ \\
& $+0,4258 \mathrm{x} 2$ & & & \\
\hline \multirow{3}{*}{ S3 } & $\mathrm{y}=14,116$ & & & \\
& $+1,5398 \mathrm{x}$ & 0,9010 & 8,23 & $<0,001^{* *}$ \\
& $+0,0167 \mathrm{x} 2$ & & & \\
\hline \multirow{3}{*}{ S4 } & $\mathrm{y}=42,41$ & & & \\
& $-0,4408 \mathrm{x}$ & 0,9083 & 14,78 & $<0,001^{* *}$ \\
& $0,5977 \mathrm{x} 2$ & & & \\
\hline
\end{tabular}

1 - Coeficiente de determinação; 2 - coeficiente de variação, 3 - nível de significância da equação 4 - Tratamento S1 - tradicional em sassafrás, Tratamento S2 - galões de polipropileno com cavacos de sassafrás e circulação forçada, Tratamento S3 - galões de polipropileno com cavacos de sassafrás, Tratamento S4 - barril de sassafrás com cavacos de sassafrás e circulação forçada, em que y é igual a acidez volátil ( $\mathrm{mg} / 100 \mathrm{~mL}$ etanol) e x é igual ao tempo em (meses).

mês de envelhecimento tradicional, tratamento $\mathrm{S}^{1}$, isso pode significar uma bebida com qualidade inferior, já que os ácidos ajudam na composição dos compostos aromáticos, não podendo, então, utilizar apenas cavacos de madeira e circulação forçada para envelhecimento da bebida. A circulação quase não acelerou o processo de envelhecimento, já que o tratamento utilizando circulação teve quase o mesmo nível de acidez que o tratamento que não utilizou. Já o tratamento $\mathrm{S}^{4}$ (tonel, cavacos e circulação), até o mês seis de envelhecimento atingiu os mesmos níveis do aumento da acidez que o tratamento tradicional, tratamento $\mathrm{S}^{1}$, durante os doze meses de envelhecimento, pode-se dizer também que o que ajudou este aumento da acidez foi a adição de cavacos de madeira juntamente com o tonel, visto que a circulação não tem muita influência na transferência.
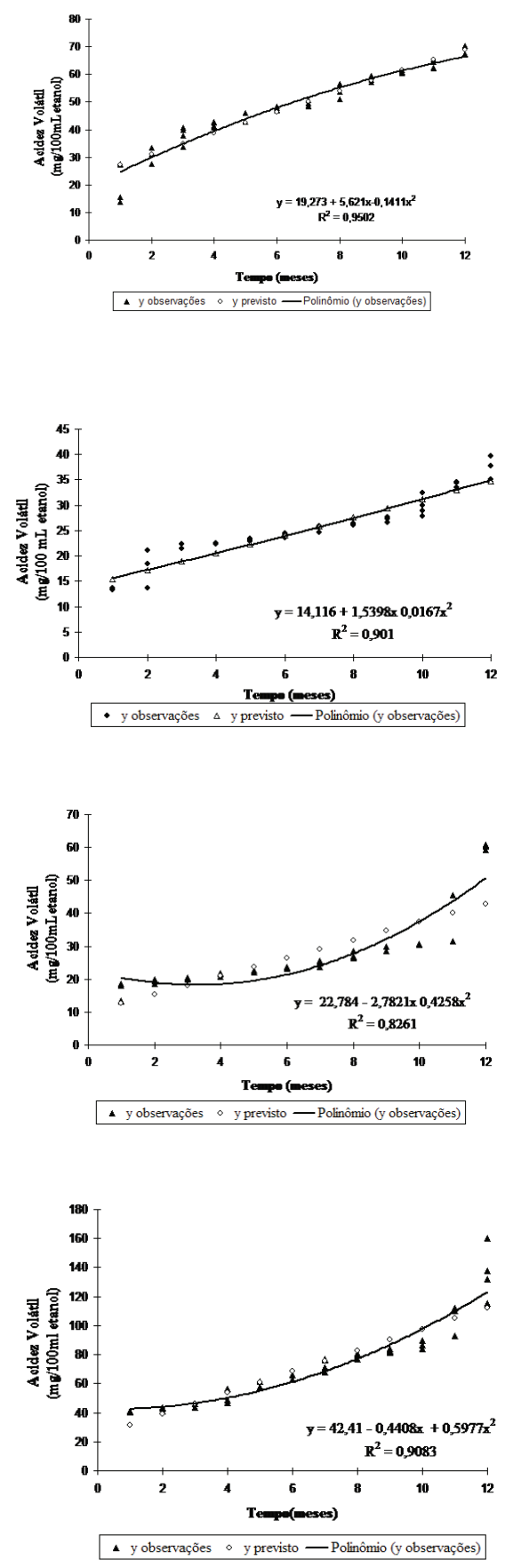

Figura 4. Evolução mensal no teor da acidez volátil das aguardentes de cana-de-açúcar envelhecidas sob os tratamentos S1 (tradicional sassafrás), S3 (galões de polipropileno com cavacos de sassafrás), S2 (galões de polipropileno com cavacos de sassafrás e circulação forçada) e S4 (barril de sassafrás com cavacos de sassafrás e circulação forçada), respectivamente em linhas. 


\section{EVOLUÇÃO DA DENSIDADE}

$\mathrm{Na}$ Tabela 7, estão apresentados os resultados médios mensais da densidade, os desvios-padrão e os coeficientes de variação das aguardentes de canade-açúcar envelhecidas sob diferentes condições no período de doze meses. Observa-se pela Tabela 7 que o tratamento $\mathrm{S}^{4}$ diferiu em quase todo o experimento de todos os tratamentos, possivelmente, pela maior área de transferência que a bebida estava exposta.

Tabela 7. Teores médios mensais, desvios-padrão e coeficientes de variação da densidade $(\mathrm{g} / \mathrm{mL})$ obtidos nos diferentes tratamentos, utilizando sassafrás durante o período de doze meses de envelhecimento.

\begin{tabular}{|c|c|c|c|c|c|}
\hline \multirow{2}{*}{ Mês } & \multicolumn{5}{|c|}{ Tratamentos } \\
\hline & S1 & S2 & $\mathrm{S} 3$ & S4 & C.V. $(\%)^{*}$ \\
\hline 1 & $\begin{array}{l}0,937 \mathrm{~b} \\
\pm 0,001\end{array}$ & $\begin{array}{c}0,939 \mathrm{a} \pm \\
0,000\end{array}$ & $\begin{array}{c}0,933 \mathrm{c} \pm \\
0,000\end{array}$ & $\begin{array}{c}0,947 \mathrm{a} \pm \\
0,000\end{array}$ & 0,075 \\
\hline 2 & $\begin{array}{c}0,940 \mathrm{~b} \\
\pm 0,000\end{array}$ & $\begin{array}{c}0,940 \mathrm{~b} \\
\pm 0,000\end{array}$ & $\begin{array}{c}0,936 \mathrm{c} \pm \\
0,001\end{array}$ & $\begin{array}{c}0,941 \mathrm{a} \pm \\
0,000\end{array}$ & 0,059 \\
\hline 3 & $\begin{array}{c}0,940 \mathrm{~b} \\
\pm 0,000\end{array}$ & $\begin{array}{c}0,941 \mathrm{c} \pm \\
0,000\end{array}$ & $\begin{array}{c}0,938 \mathrm{~d} \\
\pm 0,000\end{array}$ & $\begin{array}{c}0,942 \mathrm{a} \pm \\
0,000\end{array}$ & 0,007 \\
\hline 4 & $\begin{array}{c}0,941 b \\
\pm 0,000\end{array}$ & $\begin{array}{c}0,940 \mathrm{c} \pm \\
0,000\end{array}$ & $\begin{array}{c}0,938 \mathrm{~d} \\
\pm 0,000\end{array}$ & $\begin{array}{c}0,942 \mathrm{a} \pm \\
0,000\end{array}$ & 0,009 \\
\hline 5 & $\begin{array}{c}0,942 \mathrm{~b} \\
\pm 0,000\end{array}$ & $\begin{array}{c}0,941 \mathrm{c} \pm \\
0,000\end{array}$ & $\begin{array}{c}0,938 \mathrm{~d} \\
\pm 0,000\end{array}$ & $\begin{array}{c}0,943 \mathrm{a} \pm \\
0,000\end{array}$ & 0,005 \\
\hline 6 & $\begin{array}{c}0,941 \mathrm{c} \pm \\
0,000\end{array}$ & $\begin{array}{c}0,942 b \\
\pm 0,000\end{array}$ & $\begin{array}{c}0,938 \mathrm{~d} \\
\pm 0,000\end{array}$ & $\begin{array}{c}0,943 \mathrm{a} \pm \\
0,000\end{array}$ & 0,008 \\
\hline 7 & $\begin{array}{c}0,942 \mathrm{c} \pm \\
0,000\end{array}$ & $\begin{array}{c}0,943 b \\
\pm 0,000\end{array}$ & $\begin{array}{c}0,939 d \\
\pm 0,000\end{array}$ & $\begin{array}{c}0,944 \mathrm{a} \pm \\
0,000\end{array}$ & 0,011 \\
\hline 8 & $\begin{array}{c}0,943 \mathrm{~b} \\
\pm 0,000\end{array}$ & $\begin{array}{c}0,944 \mathrm{a} \pm \\
0,000\end{array}$ & $\begin{array}{c}0,939 \mathrm{c} \pm \\
0,000\end{array}$ & $\begin{array}{c}0,944 \mathrm{a} \pm \\
0,000\end{array}$ & 0,030 \\
\hline 9 & $\begin{array}{c}0,944 \mathrm{c} \pm \\
0,000\end{array}$ & $\begin{array}{c}0,946 \mathrm{a} \pm \\
0,000\end{array}$ & $\begin{array}{c}0,940 \mathrm{~d} \\
\pm 0,000\end{array}$ & $\begin{array}{c}0,945 b \\
\pm 0,000\end{array}$ & 0,011 \\
\hline 10 & $\begin{array}{c}0,944 \mathrm{~b} \\
\pm 0,000\end{array}$ & $\begin{array}{c}0,946 \mathrm{a} \pm \\
0,000\end{array}$ & $\begin{array}{c}0,941 \mathrm{c} \pm \\
0,000\end{array}$ & $\begin{array}{c}0,946 \mathrm{a} \pm \\
0,000\end{array}$ & 0,040 \\
\hline 11 & $\begin{array}{c}0,946 \mathrm{~b} \\
\pm 0,000\end{array}$ & $\begin{array}{c}0,946 b \\
\pm 0,000\end{array}$ & $\begin{array}{c}0,941 \mathrm{c} \pm \\
0,000\end{array}$ & $\begin{array}{c}0,949 \mathrm{a} \pm \\
0,001\end{array}$ & 0,067 \\
\hline 12 & $\begin{array}{c}0,948 \mathrm{~b} \\
\pm 0,001\end{array}$ & $\begin{array}{c}0,949 \mathrm{a}, \mathrm{b} \\
\pm 0,002\end{array}$ & $\begin{array}{c}0,949 a, b \\
\pm 0,005\end{array}$ & $\begin{array}{c}0,954 \mathrm{a} \pm \\
0,000\end{array}$ & 0,261 \\
\hline
\end{tabular}

*coeficiente variação; a,b letras iguais nas linhas significam que os tratamentos não diferiram entre si $(p>0,05)$, pelo teste de Tukey. S1 a $S 4=$ tratamentos 1 a 4 com madeira sassafrás; Tratamento 1 - envelhecimento tradicional; Tratamento 2 - galóes de polipropileno com cavacos e circulação forçada: Tratamento 3 galões de polipropileno com cavacos e tratamento 4 - barril de madeira com cavacos e circulação forçada.
Na Tabela 8, estão descritas as equações de regressão, os valores dos coeficientes de determinação (R2), coeficientes de variações (C.V.) e o nível de significância da regressão (p), nos quatro tratamentos que utilizaram a madeira sassafrás.

Tabela 8. Equações de regressão, coeficientes de determinação, coeficientes de variação e nível de significância do modelo para densidade $(\mathrm{g} / \mathrm{mL})$, das aguardentes de cana-de-açúcar envelhecidas sob diferentes tratamentos utilizando sassafrás durante doze meses.

\begin{tabular}{|c|c|c|c|c|}
\hline Tratamento $^{4}$ & Equação & $\mathbf{R}^{2(1)}$ & C.V. $^{2}$ & $\mathbf{p}^{\mathbf{3}}$ \\
\hline S1 & $\begin{array}{c}\mathrm{y}=0,9485- \\
0,001 \mathrm{x} \\
+2 \mathrm{E}-05 \mathrm{x} 2\end{array}$ & 0,8937 & 0,10 & $<0,001^{* *}$ \\
\hline \multirow{2}{*}{$\mathrm{S} 2$} & $\begin{array}{c}\mathrm{y}=0,9395 \\
+0,0002 \mathrm{x} \\
+5 \mathrm{E}-05 \mathrm{x} 2\end{array}$ & 0,9503 & 0,09 & $<0,001^{* *}$ \\
\hline \multirow{3}{*}{$\mathrm{S} 3$} & $\begin{array}{c}\mathrm{y}=0,9473- \\
0,0017 \mathrm{x}\end{array}$ & 0,662 & 0,25 & $<0,001^{* *}$ \\
& $6 \mathrm{E}-05 \mathrm{x} 2$ & & & \\
\hline \multirow{3}{*}{$\mathrm{S} 4$} & $\mathrm{y}=0,9427-$ & & & \\
& $0,0007 \mathrm{x}$ \\
& $0,0001 \mathrm{x} 2$ & 0,8967 & 0,18 & $<0,001^{* *}$ \\
\hline
\end{tabular}

1 - Coeficiente de determinação; 2 - coeficiente de variação, 3 - nivel de significância da equação 4 - Tratamento S1 - tradicional em sassafrás, Tratamento S2 - galôes de polipropileno com cavacos de sassafrás e circulação forçada, Tratamento S3 - galões de polipropileno com cavacos de sassafrás, Tratamento $S 4$ - barril de sassafrás com cavacos de sassafrás e circulação forçada, em que y é igual a densidade ( $g / m L)$ e xé igual ao tempo em (meses).

Na Figura 5, encontram-se os respectivos gráficos da evolução mensal da densidade, para os tratamentos utilizando sassafrás. Em todos os tratamentos nos quais se utilizou a madeira sassafrás, houve um aumento da densidade. Isso pode ser explicado pela transferência de compostos de alta densidade para a bebida durante o envelhecimento.

\section{EVOLUÇÃO DO GRAU ALCOÓLICO}

$\mathrm{Na}$ Tabela 9, estão apresentados os resultados médios mensais do grau alcoólico, os desvios-padrão e os coeficientes de variação das aguardentes de cana-deaçúcar envelhecidas sob diferentes condições no período de doze meses. 


\section{Artigo Geral 3}
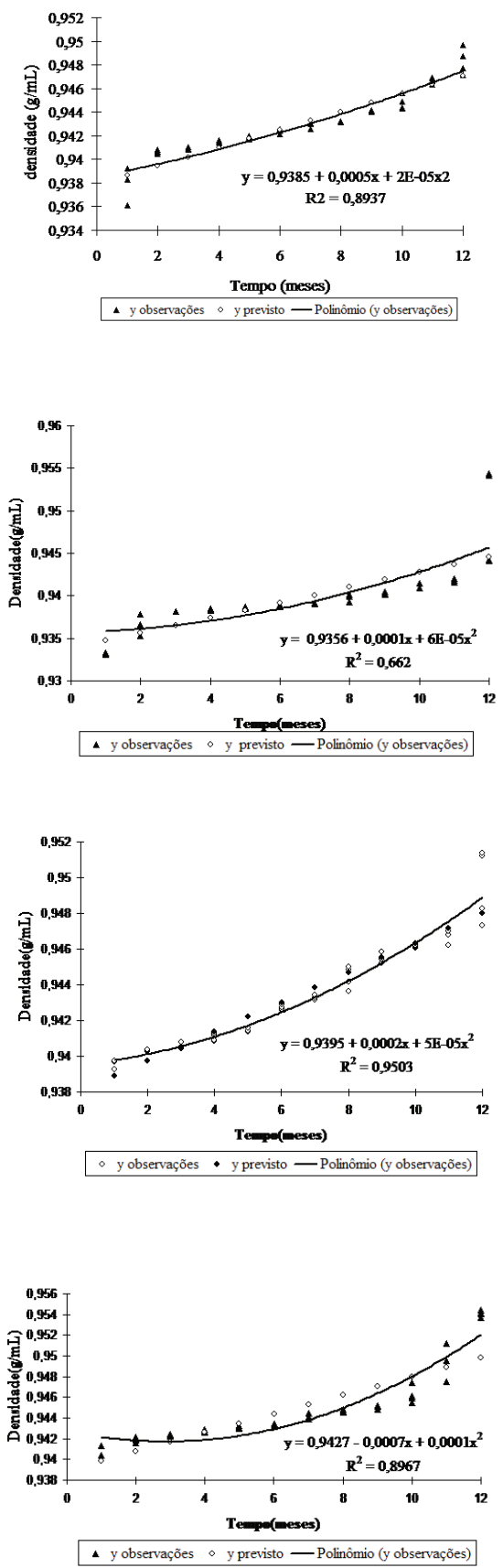

Figura 5. Evolução mensal no teor da densidade das aguardentes de cana-de-açúcar envelhecidas sob os tratamentos S1 (tradicional sassafrás), S3 (galões de polipropileno com cavacos de sassafrás), S2 (galões de polipropileno com cavacos de sassafrás e circulação forçada) e S4 (barril de sassafrás com cavacos de sassafrás e circulação forçada), respectivamente em linhas.
Tabela 9. Teores médios mensais, desvio-padrão e coeficiente de variação do grau alcoólico (\% volume) obtidos nos diferentes tratamentos, utilizando sassafrás durante o período de doze meses de envelhecimento.

\begin{tabular}{|c|c|c|c|c|c|}
\hline \multirow{2}{*}{ Mês } & \multicolumn{5}{|c|}{ Tratamentos } \\
\hline & S1 & $\mathrm{S} 2$ & S3 & $\mathrm{S} 4$ & C.V. $(\%)^{*}$ \\
\hline 1 & $\begin{array}{c}45,25 \mathrm{a}, \mathrm{b} \\
\pm 0,07\end{array}$ & $\begin{array}{c}44,90 \mathrm{~b} \\
\pm 0,56\end{array}$ & $\begin{array}{c}46,10 \mathrm{a} \pm \\
0,42\end{array}$ & $\begin{array}{l}44,40 \mathrm{~b} \\
\pm 0,14\end{array}$ & 0,51 \\
\hline 2 & $\begin{array}{c}44,50 \mathrm{a} \pm \\
0,00\end{array}$ & $\begin{array}{c}44,50 \mathrm{a} \\
\pm 0,84\end{array}$ & $\begin{array}{c}45,65 \mathrm{a} \pm \\
0,07\end{array}$ & $\begin{array}{l}43,90 \mathrm{a} \\
\pm 0,28\end{array}$ & 0,86 \\
\hline 3 & $\begin{array}{c}44,30 \mathrm{a}, \mathrm{b} \\
\pm 0,21\end{array}$ & $\begin{array}{c}44,10 \mathrm{a}, \mathrm{b} \\
\pm 0,84\end{array}$ & $\begin{array}{c}45,50 \mathrm{a} \pm \\
0,00\end{array}$ & $\begin{array}{l}43,10 \mathrm{~b} \\
\pm 0,00\end{array}$ & 1,06 \\
\hline 4 & $\begin{array}{l}43,70 \mathrm{~b} \\
\pm 0,14\end{array}$ & $\begin{array}{c}43,40 \mathrm{~b}, \mathrm{c} \\
\pm 0,14\end{array}$ & $\begin{array}{c}45,35 \mathrm{a} \pm \\
0,07\end{array}$ & $\begin{array}{l}43,00 \mathrm{c} \\
\pm 0,00\end{array}$ & 0,27 \\
\hline 5 & $\begin{array}{c}43,35 b \\
\pm 0,070\end{array}$ & $\begin{array}{l}42,15 \mathrm{~d} \\
\pm 0,07\end{array}$ & $\begin{array}{c}45,10 \mathrm{a} \pm \\
0,00\end{array}$ & $\begin{array}{l}42,85 \mathrm{c} \\
\pm 0,07\end{array}$ & 0,15 \\
\hline 6 & $\begin{array}{l}42,70 \mathrm{~b} \\
\pm 0,00\end{array}$ & $\begin{array}{l}41,70 \mathrm{~d} \\
\pm 0,00\end{array}$ & $\begin{array}{c}44,95 \mathrm{a} \pm \\
0,07\end{array}$ & $\begin{array}{l}42,30 \mathrm{c} \\
\pm 0,14\end{array}$ & 0,15 \\
\hline 7 & $\begin{array}{l}42,65 \mathrm{~b} \\
\pm 0,07\end{array}$ & $\begin{array}{l}41,05 \mathrm{c} \\
\pm 0,49\end{array}$ & $\begin{array}{c}44,80 \mathrm{a} \pm \\
0,00\end{array}$ & $\begin{array}{c}41,70 \mathrm{~b}, \mathrm{c} \\
\pm 0,00\end{array}$ & 0,55 \\
\hline 8 & $\begin{array}{l}42,40 \mathrm{~b} \\
\pm 0,21\end{array}$ & $\begin{array}{l}40,50 \mathrm{~d} \\
\pm 0,14\end{array}$ & $\begin{array}{c}44,65 \mathrm{a} \pm \\
0,21\end{array}$ & $\begin{array}{l}41,50 \mathrm{c} \\
\pm 0,21\end{array}$ & 0,41 \\
\hline 9 & $\begin{array}{l}42,30 \mathrm{~b} \\
\pm 0,00\end{array}$ & $\begin{array}{l}40,10 \mathrm{c} \\
\pm 0,70\end{array}$ & $\begin{array}{c}44,45 \mathrm{a} \pm \\
0,07\end{array}$ & $\begin{array}{c}41,10 \mathrm{~b}, \mathrm{c} \\
\pm 0,21\end{array}$ & 0,78 \\
\hline 10 & $\begin{array}{l}42,05 \mathrm{~b} \\
\pm 0,07\end{array}$ & $\begin{array}{l}39,45 \mathrm{c} \\
\pm 0,35\end{array}$ & $\begin{array}{c}44,40 \mathrm{a} \pm \\
0,00\end{array}$ & $\begin{array}{c}40,60 \mathrm{c} \pm \\
0,28\end{array}$ & 0,63 \\
\hline 11 & $\begin{array}{c}38,95 \mathrm{~b}, \mathrm{c} \\
\pm 0,63\end{array}$ & $\begin{array}{l}38,30 \mathrm{c} \\
\pm 0,28\end{array}$ & $\begin{array}{c}44,15 \mathrm{a} \pm \\
0,21\end{array}$ & $\begin{array}{l}40,20 \mathrm{~b} \\
\pm 0,28\end{array}$ & 0,93 \\
\hline 12 & $\begin{array}{l}36,60 \mathrm{~b} \\
\pm 1,41\end{array}$ & $\begin{array}{l}38,75 b \\
\pm 0,21\end{array}$ & $\begin{array}{c}43,85 \mathrm{a} \pm \\
0,21\end{array}$ & $\begin{array}{l}39,30 \mathrm{~b} \\
\pm 0,28\end{array}$ & 1,97 \\
\hline
\end{tabular}

*coeficiente variação; a,b letras iguais nas linhas significam que os tratamentos não diferiram entre si ( $p>0,05)$, pelo teste de Tukey. S1 a $S 4=$ tratamentos 1 a 4 com madeira sassafrás; Tratamento 1 - envelhecimento tradicional; Tratamento 2 - galóes de polipropileno com cavacos e circulação forçada; Tratamento 3 galões de polipropileno com cavacos e tratamento 4 - barril de madeira com cavacos e circulação forçada.

Estudos realizados em dez amostras sem envelhecer e dez amostras envelhecidas com relação ao perfil quantitativo do grau alcoólico e dos teores de cobre e de açúcares em cachaças comerciais mostraram que nas amostras envelhecidas o teor de álcool variava de $38,3 \%$ a $46,6 \%$ volume enquanto que nas amostras sem envelhecer o teor alcoólico encontrado ficou entre $34,6 \%$ a $41,8 \%$ volume. Neste estudo, verificou-se também que das cachaças analisadas, apenas três amostras sem envelhecer encontravam-se fora do padrão da legislação vigente ${ }^{12}$. 
$\mathrm{Na}$ Tabela 10, estão descritas as equações de regressão, os valores dos coeficientes de determinação (R2), coeficientes de variações (C.V.) e o nível de significância da regressão $(\mathrm{p})$, nos quatro tratamentos que utilizaram a madeira sassafrás. Na Figura 6, encontramse os respectivos gráficos da evolução mensal do grau alcoólico, para os tratamentos utilizando sassafrás.

Tabela 10. Equações de regressão, coeficientes de determinação, coeficientes de variação e nível de significância do modelo para grau alcoólico (\% volume), das aguardentes de cana-de-açúcar envelhecidas sob diferentes tratamentos utilizando sassafrás durante doze meses.

\begin{tabular}{|c|c|c|c|c|}
\hline Tratamento $^{4}$ & Equação & $\mathbf{R}^{2(1)}$ & C.V. ${ }^{2}$ & $\mathbf{p}^{3}$ \\
\hline S1 & $\begin{array}{c}\mathrm{y}=44,340+ \\
0,23674 \mathrm{x}- \\
0,063 \times 2\end{array}$ & 0,8661 & 2,65 & $<0,001 * *$ \\
\hline S2 & $\begin{array}{c}y=45,939 \\
-0,7581 x+ \\
0,0104 x 2\end{array}$ & 0,9604 & 1,10 & $<0,001 * *$ \\
\hline S3 & $\begin{array}{c}y=43,819 \\
+0,1441 x+ \\
0,0029 x 2\end{array}$ & 0,9529 & 0,33 & $<0,001 * *$ \\
\hline S4 & $\begin{array}{c}\mathrm{y}=44,562- \\
0,344 \mathrm{x}- \\
0,0063 \times 2\end{array}$ & 0,9782 & 0,56 & $<0,001 * *$ \\
\hline
\end{tabular}

1 - coeficiente de determinação; 2 - coeficiente de variação, 3 - nivel de significância da equação 4 - Tratamento $S 1$ - tradicional em sassafrás, Tratamento S2 - galões de polipropileno com cavacos de sassafrás e circulação forçada, Tratamento S3 - galões de polipropileno com cavacos de sassafrás, Tratamento S4 - barril de sassafrás com cavacos de sassafrás e circulação forçada, em que y é igual ao grau alcoólico (\% volume) e x é igual ao tempo em (meses).

$\mathrm{O}$ tratamento $\mathrm{S}_{1}$ a $\mathrm{S}_{4}$ que se utilizou da madeira sassafrás obtiveram-se coeficientes de variação baixos, de 0,33 a 2,65 indicando assim uma ótima precisão do experimento em relação ao grau alcoólico.Todos os tratamentos tiveram um crescimento de forma polinomial.

Alguns autores estudaram a radiação gama na aguardente de cana-de-açúcar e analisaram cinco aguardentes de cana-de-açúcar diferentes. As aguardentes de cana-de-açúcar foram transferidas de suas embalagens originais para frascos de vidro e tonéis de carvalho, em que foram irradiadas com doses de 0,0, 0,1, 2,0, 5,0 e 10,0 KGy. A graduação alcoólica foi medida no alcoômetro de Gay-Lussac segundo normas do Instituto Adolfo Lutz.
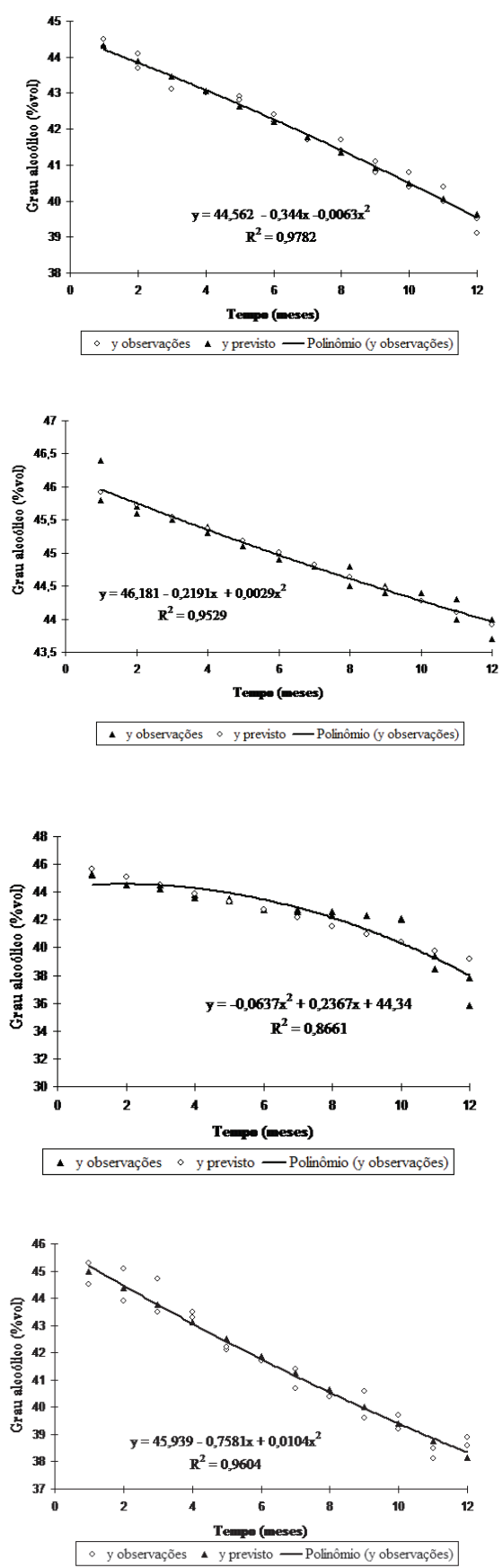

Figura 6. Evolução mensal no teor do grau alcoólico das aguardentes de cana-de-açúcar envelhecidas sob os tratamentos S1 (tradicional sassafrás), S3 (galões de polipropileno com cavacos de sassafrás), S2 (galões de polipropileno com cavacos de sassafrás e circulação forçada) e S4 (barril de sassafrás com cavacos de sassafrás e circulação forçada), respectivamente em linhas. 
Em todas as amostras, a radiação fez com que o grau alcoólico da bebida diminuísse. O autor verificou também que houve uma correlação entre as doses de radiações aplicadas e as concentrações do grau alcoólico ${ }^{13}$.

Os tratamentos $\mathrm{S}_{1}$ e $\mathrm{S}_{4}$ (barril de madeira) tiveram um decréscimo durante os doze meses de envelhecimento, isto pode ser explicado devido à alta porosidade da madeira utilizada, ajudando na evaporação da água e do álcool. Já os tratamentos $\mathrm{S}_{2}$ e $\mathrm{S}_{3}$ (embalagens de polipropileno) tiveram uma diminuição no teor alcoólico. Possivelmente, porque as embalagens não ficaram protegidas da incidência da luz solar, aumentando, então, a perda por evaporação da fração de álcool e água, diminuindo o grau alcoólico.

\section{EVOLUÇÃO DOS COMPOSTOS DO DESTILADO DO CONTROLE (VIDRO) DOS TRATAMENTOS EM GALÃO DE POLIPROPILENO COM CIRCULAÇÃO FORÇADA E ESTÁTICO}

\section{Evolução do extrato seco}

Na Tabela 11, estão apresentados os valores médios mensais do extrato seco, os desvios-padrão e os coeficientes de variação da aguardente de cana-de-açúcar armazenada sob diferentes condições no período de doze meses.

Todos os tratamentos diferiram $(\mathrm{p} \leq 0,05)$ entre si nos meses dois, quatro, cinco e sete a doze. No mês um, o tratamento padrão $(\mathrm{P})$ diferiu $(\mathrm{p} \leq 0,05)$ do tratamento $\mathrm{PP}$ e PPc. Nos meses três e seis diferiu $(\mathrm{p} \leq 0,05)$ do tratamento PPc. Entre os tratamentos PPc e PP nos meses três e seis diferiram $(\mathrm{p} \leq 0,05)$ entre si e no mês um não diferiram $(\mathrm{p}>0,05)$.

$\mathrm{Na}$ Tabela 12, estão os valores da equação de regressão, os valores do coeficiente de determinação (R2), coeficientes de variação (C.V.) e nível de significância da regressão (p) nos tratamentos PP e PPc durante os doze meses de envelhecimento. Na Figura 7, estão apresentados os gráficos da evolução mensal do extrato seco, para os tratamentos.

Nos tratamentos PPc e PP observou-se um aumento do teor de extrato seco quase que constante e de forma polinomial. Obteve-se um R2 0,9277 e 0,9753, respectivamente. A transferência de extrato seco foi muito, baixa devido à falta de madeira, podendo-se verificar, então, que o galão plástico de polipropileno não influencia no envelhecimento da bebida.
Tabela 11. Teores médios mensais, desvio-padrão e coeficiente de variação do teor de extrato seco $(\mathrm{g} / \mathrm{mL})$ obtidos nos diferentes tratamentos, utilizando galões de polipropileno durante o período de doze meses de envelhecimento.

\begin{tabular}{|c|c|c|c|c|c|}
\hline \multirow{2}{*}{ Mês } & \multicolumn{5}{|c|}{ Tratamentos } \\
\cline { 2 - 6 } & $\mathrm{S} 1$ & $\mathrm{~S} 2$ & $\mathrm{~S} 3$ & $\mathrm{~S} 4$ & C.V.(\%)* \\
\hline 1 & $\begin{array}{c}0,01 \mathrm{~b} \pm \\
0,00\end{array}$ & $\begin{array}{c}0,01 \mathrm{~b} \pm \\
0,00\end{array}$ & $\begin{array}{c}0,05 \mathrm{a} \pm \\
0,00\end{array}$ & 11,93 & 0,51 \\
\hline 2 & $\begin{array}{c}0,01 \mathrm{c} \pm \\
0,00\end{array}$ & $\begin{array}{c}0,02 \mathrm{~b} \pm \\
0,00\end{array}$ & $\begin{array}{c}0,05 \mathrm{a} \pm \\
0,00\end{array}$ & 6,74 & 0,86 \\
\hline 3 & $\begin{array}{c}0,02 \mathrm{~b} \pm \\
0,00\end{array}$ & $\begin{array}{c}0,04 \mathrm{a} \pm \\
0,00\end{array}$ & $\begin{array}{c}0,05 \mathrm{a} \pm \\
0,00\end{array}$ & 9,86 & 1,06 \\
\hline 4 & $\begin{array}{c}0,02 \mathrm{c} \pm \\
0,00\end{array}$ & $\begin{array}{c}0,06 \mathrm{a} \pm \\
0,00\end{array}$ & $\begin{array}{c}0,05 \mathrm{~b} \pm \\
0,00\end{array}$ & 5,65 & 0,27 \\
\hline 5 & $\begin{array}{c}0,04 \mathrm{c} \pm \\
0,00\end{array}$ & $\begin{array}{c}0,07 \mathrm{a} \pm \\
0,00\end{array}$ & $\begin{array}{c}0,05 \mathrm{~b} \pm \\
0,00\end{array}$ & 5,05 & 0,15 \\
\hline 6 & $\begin{array}{c}0,05 \mathrm{~b} \pm \\
0,00\end{array}$ & $\begin{array}{c}0,08 \mathrm{a} \pm \\
0,00\end{array}$ & $\begin{array}{c}0,05 \mathrm{~b} \pm \\
0,00\end{array}$ & 4,14 & 0,15 \\
\hline 7 & $\begin{array}{c}0,06 \mathrm{~b} \pm \\
0,00\end{array}$ & $\begin{array}{c}0,09 \mathrm{a} \pm \\
0,00\end{array}$ & $\begin{array}{c}0,05 \mathrm{c} \pm \\
0,00\end{array}$ & 3,65 & 0,55 \\
\hline 8 & $\begin{array}{c}0,09 \mathrm{~b} \pm \\
0,00\end{array}$ & $\begin{array}{c}0,12 \mathrm{a} \pm \\
0,00\end{array}$ & $\begin{array}{c}0,05 \mathrm{c} \pm \\
0,00\end{array}$ & 4,38 & 0,41 \\
\hline 9 & $\begin{array}{c}0,08 \mathrm{~b} \pm \\
0,00\end{array}$ & $\begin{array}{c}0,13 \mathrm{a} \pm \\
0,00\end{array}$ & $\begin{array}{c}0,05 \mathrm{c} \pm \\
0,00\end{array}$ & 5,41 & 0,78 \\
\hline 10 & $\begin{array}{c}0,08 \mathrm{~b} \pm \\
0,00\end{array}$ & $\begin{array}{c}0,13 \mathrm{a} \pm \\
0,00\end{array}$ & $\begin{array}{c}0,05 \mathrm{c} \pm \\
0,00\end{array}$ & 7,94 & 0,63 \\
\hline 11 & $\begin{array}{c}0,09 \mathrm{~b} \pm \\
0,00\end{array}$ & $\begin{array}{c}0,17 \mathrm{a} \pm \\
0,00\end{array}$ & $\begin{array}{c}0,05 \mathrm{c} \pm \\
0,00\end{array}$ & 7,27 & 0,93 \\
\hline 0,00 & $\begin{array}{c}0,18 \mathrm{a} \pm \\
0,00\end{array}$ & $\begin{array}{c}0,05 \mathrm{c} \pm \\
0,00\end{array}$ & 5,55 & 1,97 \\
\hline
\end{tabular}

*coeficiente variação; a,b letras iguais nas linhas significam que os tratamentos não diferiram entre si $(p>0,05)$, pelo teste de Tukey. S1 a S4 = tratamentos 1 a 4 com madeira sassafrás; Tratamento 1 - envelhecimento tradicional; Tratamento 2 - galões de polipropileno com cavacos e circulação forçada; Tratamento 3 galões de polipropileno com cavacos e tratamento 4 - barril de madeira com cavacos e circulação forçada.

Tabela 12. Equações de regressão, coeficientes de determinação, coeficientes de variação e nível de significância do modelo para extrato $\operatorname{seco}(\mathrm{g} / \mathrm{L})$, das aguardentes de cana-de-açúcar envelhecidas sob diferentes tratamentos utilizando galões de polipropileno durante doze meses.

\begin{tabular}{|c|c|c|c|c|}
\hline Tratamento $^{4}$ & Equação & $\mathbf{R}^{2(\mathbf{1})}$ & C.V. $^{2}$ & $\mathbf{p}^{\mathbf{3}}$ \\
\hline \multirow{3}{*}{$\mathrm{PPC}$} & $\mathrm{y}=-0,0154$ & & & \\
& $+0,0154 \mathrm{x}-$ & 0,9277 & 18,14 & $0,96 \mathrm{~ns}$ \\
& $0,0005 \mathrm{x} 2$ & & & \\
\hline \multirow{3}{*}{$\mathrm{PP}$} & $\mathrm{y}=-0,0008$ & & & \\
& $+0,0132+$ & 0,9753 & 39,80 & $0,02 \mathrm{~ns}$ \\
\hline
\end{tabular}

1 - coeficiente de determinação; 2 - coeficiente de variação, 3 - nível de significância da equação 4 - Tratamento PPc -galões de polipropileno com circulação forçada, Tratamento PP - galões de polipropileno estático, em que yé igual ao teor de extrato seco $(g / L)$ e xé igual ao tempo em (meses). 

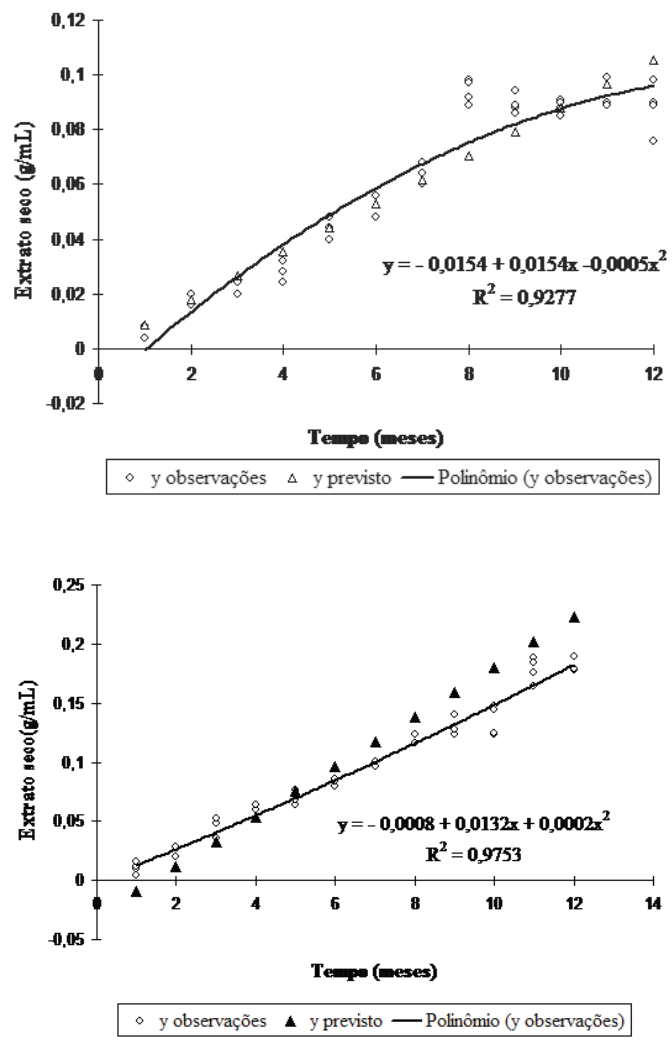

Figura 7. Evolução mensal no teor do extrato seco das aguardentes de cana-de-açúcar envelhecidas sob os tratamentos PPc (galões de polipropileno com circulação forçada) e PP (galões de polipropileno estático), respectivamente.

Nestes tratamentos, pode-se constatar que o bombeamento não influencia na transferência de extrato para a bebida.

\section{Evolução da acidez volátil}

$\mathrm{Na}$ Tabela 13, estão apresentados os valores médios mensais da acidez volátil, os desvios-padrão e os coeficientes de variação da aguardente de cana-de-açúcar armazenada sob diferentes condições no período de doze meses.

Em relação à análise estatística, os tratamentos PPc e PP apenas diferiram $(\mathrm{p} \leq 0,05)$ entre si nos meses dois, três e oito. $O$ tratamento padrão $(P)$ diferiu $(\mathrm{p} \leq 0,05)$ em todos os meses dos outros dois tratamentos.
Tabela 13. Teores médios mensais, desvio-padrão e coeficiente de variação da acidez volátil $(\mathrm{mg} / 100 \mathrm{~mL}$ etanol) obtidos nos diferentes tratamentos, utilizando galões de polipropileno durante o período de doze meses de envelhecimento.

\begin{tabular}{|c|c|c|c|c|c|}
\hline \multirow{2}{*}{ Mês } & \multicolumn{5}{|c|}{ Tratamentos } \\
\hline & $\mathrm{S} 1$ & S2 & S3 & S4 & C.V. $(\%)^{*}$ \\
\hline 1 & $\begin{array}{c}13,43 \mathrm{a} \pm \\
0,18\end{array}$ & $\begin{array}{c}13,11 \mathrm{a} \pm \\
0,46\end{array}$ & $\begin{array}{l}11,10 \mathrm{~b} \\
\pm 0,00\end{array}$ & 2,05 & 0,51 \\
\hline 2 & $\begin{array}{c}15,30 \mathrm{a} \\
\pm 0,61\end{array}$ & $\begin{array}{l}13,41 b \\
\pm 0,04\end{array}$ & $\begin{array}{c}11,10 \mathrm{c} \pm \\
0,00\end{array}$ & 2,57 & 0,86 \\
\hline 3 & $\begin{array}{c}16,94 \mathrm{a} \pm \\
0,28\end{array}$ & $\begin{array}{l}15,51 b \\
\pm 0,83\end{array}$ & $\begin{array}{c}11,10 \mathrm{c} \pm \\
0,00\end{array}$ & 2,93 & 1,06 \\
\hline 4 & $\begin{array}{c}17,83 \mathrm{a} \pm \\
0,46\end{array}$ & $\begin{array}{l}17,50 \mathrm{a} \\
\pm 0,06\end{array}$ & $\begin{array}{l}11,10 \mathrm{~b} \\
\pm 0,00\end{array}$ & 1,65 & 0,27 \\
\hline 5 & $\begin{array}{c}16,68 \mathrm{a} \pm \\
0,47\end{array}$ & $\begin{array}{c}18,31 \mathrm{a} \pm \\
0,60\end{array}$ & $\begin{array}{l}11,10 \mathrm{~b} \\
\pm 0,00\end{array}$ & 2,14 & 0,15 \\
\hline 6 & $\begin{array}{c}19,80 \mathrm{a} \pm \\
0,30\end{array}$ & $\begin{array}{c}19,57 \mathrm{a} \pm \\
0,41\end{array}$ & $\begin{array}{l}11,10 \mathrm{~b} \\
\pm 0,00\end{array}$ & 1,29 & 0,15 \\
\hline 7 & $\begin{array}{c}21,78 \mathrm{a} \pm \\
1,15\end{array}$ & $\begin{array}{c}21,27 \mathrm{a} \pm \\
0,49\end{array}$ & $\begin{array}{l}11,10 \mathrm{~b} \\
\pm 0,00\end{array}$ & 3,22 & 0,55 \\
\hline 8 & $\begin{array}{c}23,89 \mathrm{a} \pm \\
0,93\end{array}$ & $\begin{array}{c}22,09 b \\
\pm 0,21\end{array}$ & $\begin{array}{c}11,10 \mathrm{c} \pm \\
0,00\end{array}$ & 2,63 & 0,41 \\
\hline 9 & $\begin{array}{c}26,04 \mathrm{a} \pm \\
0,76\end{array}$ & $\begin{array}{c}24,81 \mathrm{a} \pm \\
2,29\end{array}$ & $\begin{array}{l}11,10 \mathrm{~b} \\
\pm 0,00\end{array}$ & 6,05 & 0,78 \\
\hline 10 & $\begin{array}{c}27,65 \mathrm{a} \pm \\
0,25\end{array}$ & $\begin{array}{c}27,37 \mathrm{a} \pm \\
0,39\end{array}$ & $\begin{array}{l}11,10 \mathrm{~b} \\
\pm 0,00\end{array}$ & 0,92 & 0,63 \\
\hline 11 & $\begin{array}{c}29,14 \mathrm{a} \pm \\
1,30\end{array}$ & $\begin{array}{c}28,71 \mathrm{a} \pm \\
0,51\end{array}$ & $\begin{array}{l}11,10 \mathrm{~b} \\
\pm 0,00\end{array}$ & 2,88 & 0,93 \\
\hline 12 & $\begin{array}{c}39,22 \mathrm{a} \pm \\
4,58\end{array}$ & $\begin{array}{c}39,15 \mathrm{a} \pm \\
6,53\end{array}$ & $\begin{array}{l}11,10 \mathrm{~b} \\
\pm 0,00\end{array}$ & 11,26 & 1,97 \\
\hline
\end{tabular}

* Coeficientes de variação; a,b letras iguais nas linhas significam que os tratamentos não diferiram entre si $(p>0,05)$, pelo teste de tukey. PPc-galões de polipropileno com circulação forçada. PP - galóes de polipropileno estático;

A Tabela 14 contém os valores da equação de regressão, do coeficiente de determinação (R2), coeficientes de variação (C.V.) e nível de significância da regressão (p) nos tratamentos PP e PPc durante os doze meses de envelhecimento. Na Figura 8, estão mostrados os gráficos da evolução mensal da acidez volátil, para os tratamentos.

O tratamento PPc e PP foram os tratamentos para controle do galão de polipropilenos (PP) e para controle da utilização da circulação forçada (PPc). 


\section{Artigo Geral 3}
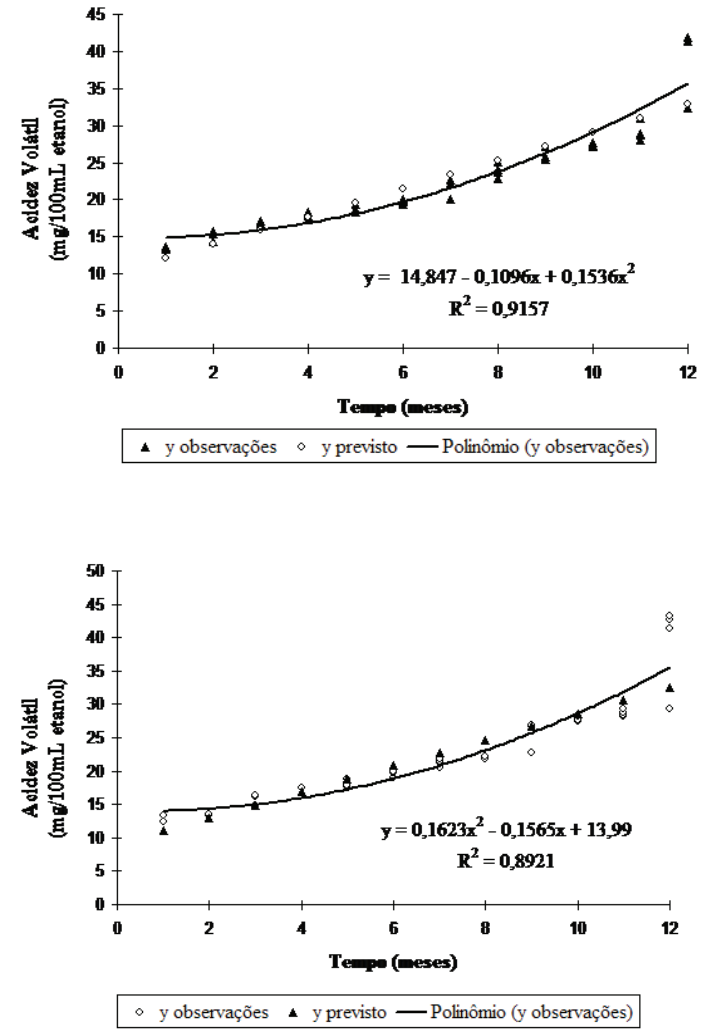

Figura 8. Evolução mensal no teor da acidez volátil das aguardentes de cana-de-açúcar envelhecidas sob os tratamentos PPc (galões de polipropileno com circulação forçada) e PP (galões de polipropileno estático), respectivamente.

Nos dois tratamentos, a acidez volátil da aguardente de cana-de-açúcar aumentou durante o período de doze meses. O bombeamento não interferiu nos dois tratamentos que tiveram o mesmo aumento da acidez.

\section{Evolução da densidade}

$\mathrm{Na}$ Tabela 15, estão apresentados os valores médios mensais da densidade, os desvios-padrão e os coeficientes de variação da aguardente de cana-de-açúcar armazenada sob diferentes condições no período de doze meses. Observa-se que todos os tratamentos, com exceção do mês dois, diferiram $(\mathrm{p} \leq 0,05)$ entre si em todos os demais meses, para os tratamentos PPc e PP.
Tabela 15. Teores médios mensais, desvios-padrão e coeficientes de variação da densidade $(\mathrm{g} / \mathrm{mL})$ obtidos nos diferentes tratamentos, utilizando galões de polipropileno durante o período de doze meses de envelhecimento.

\begin{tabular}{|c|c|c|c|c|c|}
\hline \multirow{2}{*}{ Mês } & \multicolumn{5}{|c|}{ Tratamentos } \\
\hline & $\mathrm{S} 1$ & $\mathrm{~S} 2$ & $\mathrm{~S} 3$ & S4 & C.V. $(\%)^{*}$ \\
\hline 1 & $\begin{array}{c}0,936 \mathrm{a} \pm \\
0,000\end{array}$ & $\begin{array}{c}0,933 b \\
\pm 0,000\end{array}$ & $\begin{array}{c}0,860 \mathrm{c} \pm \\
0,000\end{array}$ & 0,052 & 0,51 \\
\hline 2 & $\begin{array}{l}0,938 \mathrm{a} \\
\pm 0,000\end{array}$ & $\begin{array}{c}0,937 \mathrm{a} \pm \\
0,000\end{array}$ & $\begin{array}{c}0,860 \mathrm{~b} \\
\pm 0,000\end{array}$ & 0,025 & 0,86 \\
\hline 3 & $\begin{array}{c}0,939 \mathrm{a} \pm \\
0,000\end{array}$ & $\begin{array}{c}0,938 \mathrm{~b} \\
\pm 0,000\end{array}$ & $\begin{array}{c}0,860 \mathrm{c} \pm \\
0,000\end{array}$ & 0,016 & 1,06 \\
\hline 4 & $\begin{array}{c}0,939 \mathrm{a} \pm \\
0,000\end{array}$ & $\begin{array}{c}0,938 b \\
\pm 0,000\end{array}$ & $\begin{array}{c}0,860 \mathrm{c} \pm \\
0,000\end{array}$ & 0,010 & 0,27 \\
\hline 5 & $\begin{array}{c}0,940 \mathrm{a} \pm \\
0,000\end{array}$ & $\begin{array}{c}0,938 b \\
\pm 0,000\end{array}$ & $\begin{array}{c}0,860 \mathrm{c} \pm \\
0,000\end{array}$ & 0,007 & 0,15 \\
\hline 6 & $\begin{array}{c}0,940 \mathrm{a} \pm \\
0,000\end{array}$ & $\begin{array}{c}0,938 b \\
\pm 0,000\end{array}$ & $\begin{array}{c}0,860 \mathrm{c} \pm \\
0,000\end{array}$ & 0,015 & 0,15 \\
\hline 7 & $\begin{array}{c}0,941 \mathrm{a} \pm \\
0,000\end{array}$ & $\begin{array}{c}0,939 b \\
\pm 0,000\end{array}$ & $\begin{array}{c}0,860 \mathrm{c} \pm \\
0,000\end{array}$ & 0,020 & 0,55 \\
\hline 8 & $\begin{array}{c}0,941 \mathrm{a} \pm \\
0,000\end{array}$ & $\begin{array}{c}0,940 \mathrm{~b} \\
\pm 0,000\end{array}$ & $\begin{array}{c}0,860 \mathrm{c} \pm \\
0,000\end{array}$ & 0,006 & 0,41 \\
\hline 9 & $\begin{array}{c}0,941 \mathrm{a} \pm \\
0,000\end{array}$ & $\begin{array}{c}0,940 \mathrm{~b} \\
\pm 0,000\end{array}$ & $\begin{array}{c}0,860 \mathrm{c} \pm \\
0,000\end{array}$ & 0,006 & 0,78 \\
\hline 10 & $\begin{array}{c}0,941 \mathrm{a} \pm \\
0,000\end{array}$ & $\begin{array}{c}0,940 \mathrm{~b} \\
\pm 0,000\end{array}$ & $\begin{array}{c}0,860 \mathrm{c} \pm \\
0,000\end{array}$ & 0,012 & 0,63 \\
\hline 11 & $\begin{array}{c}0,942 \mathrm{a} \pm \\
0,000\end{array}$ & $\begin{array}{c}0,941 b \\
\pm 0,000\end{array}$ & $\begin{array}{c}0,860 \mathrm{c} \pm \\
0,000\end{array}$ & 0,033 & 0,93 \\
\hline 12 & $\begin{array}{c}0,943 \mathrm{~b} \\
\pm 0,000\end{array}$ & $\begin{array}{c}0,949 \mathrm{a} \pm \\
0,003\end{array}$ & $\begin{array}{c}0,860 \mathrm{c} \pm \\
0,000\end{array}$ & 0,188 & 1,97 \\
\hline
\end{tabular}

* Coeficiente de variação; a,b letras iguais nas linhas significam que os tratamentos não diferiram entre si $(p>0,05)$, pelo teste de Tukey. PPc - galóes de polipropileno com circulação forçada. PP - galóes de polipropileno estático;

$\mathrm{Na}$ Tabela 16, estão apresentados os valores da equação de regressão, os valores do coeficiente de determinação (R2), coeficientes de variação (C.V.) e o nível de significância da regressão (p) nos tratamentos PP e PPc durante os doze meses de envelhecimento.

Os tratamentos PPc e PP são tratamentos padrões, que tiveram a densidade aumentada durante os doze meses de tratamento. O tratamento PPc (galão de polipropileno com circulação forçada) teve uma diminuição do grau alcoólico, apesar do galão impermeável, esta diminuição pode ter influenciado no aumento da densidade durante o envelhecimento. 
Tabela 16. Equações de regressão, coeficientes de determinação, coeficientes de variação e nível de significância do modelo para densidade $(\mathrm{g} / \mathrm{mL})$, das aguardentes de cana-de-açúcar envelhecidas sob diferentes tratamentos utilizando galões de polipropileno durante doze meses.

\begin{tabular}{|c|c|c|c|c|}
\hline Tratamento $^{4}$ & Equação & $\mathbf{R}^{2(1)}$ & C.V. $^{2}$ & $\mathbf{p}^{3}$ \\
\hline \multirow{3}{*}{$\mathrm{PPc}$} & $\mathrm{y}=0,9364$ & & & \\
& $\begin{array}{c}3 \mathrm{E}-05 \mathrm{x}+ \\
7 \mathrm{E}-05 \mathrm{x} 2\end{array}$ & 0,6983 & 0,2350 & $<0,001^{* *}$ \\
\hline \multirow{3}{*}{$\mathrm{PP}$} & $\begin{array}{c}\mathrm{y}=0,9432 \\
-0,0002 \mathrm{x}- \\
2 \mathrm{E}-05 \mathrm{x} 2\end{array}$ & 0,9506 & 0,05 & $<0,001^{* *}$ \\
& & & \\
\hline
\end{tabular}

1 - coeficiente de determinação; 2 - coeficiente de variação, 3 - nível de significância da equação 4 - Tratamento PPc -galões de polipropileno com circulação forçada, Tratamento PP - galões de polipropileno estático, onde y é igual a densidade $(\mathrm{g} / \mathrm{mL})$ e x é igual ao tempo em (meses).

Na Figura 9, estão mostrados os gráficos da evolução mensal da densidade para os tratamentos.
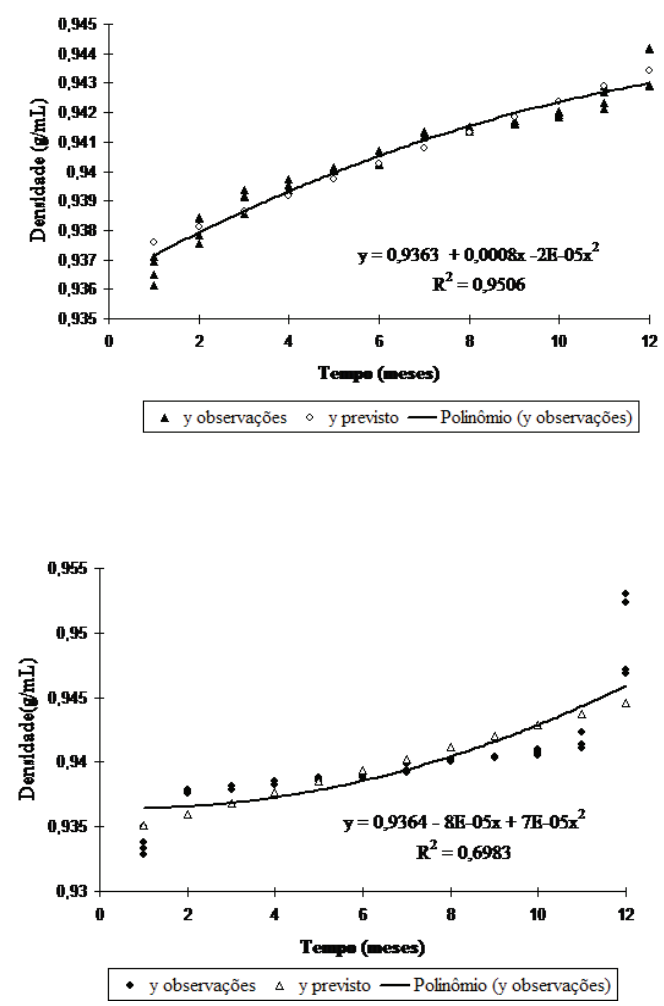

Figura 9. Evolução mensal no teor da densidade das aguardentes de canade-açúcar envelhecidas sob os tratamentos PPc (galões de polipropileno com circulação forçada) e PP (galões de polipropileno estático), respectivamente.

\section{Evolução do grau alcoólico}

$\mathrm{Na}$ Tabela 17, estão apresentados os valores médios mensais do grau alcoólico, os desvios-padrão e os coeficientes de variação das aguardentes de cana-de-açúcar armazenadas sob diferentes condições no período de doze meses.

Tabela 17. Teores médios mensais, desvio padrão e coeficiente de variação do grau alcoólico (\% volume) obtidos nos diferentes tratamentos, utilizando galões de polipropileno durante o período de doze meses de envelhecimento.

\begin{tabular}{|c|c|c|c|c|c|}
\hline \multirow{2}{*}{ Mês } & \multicolumn{5}{|c|}{ Tratamentos } \\
\cline { 2 - 6 } & S1 & S2 & S3 & S4 & C.V.(\%)* \\
\hline 1 & $\begin{array}{c}45,20 \mathrm{a} \pm \\
0,00\end{array}$ & $\begin{array}{c}44,10 \mathrm{~b} \\
\pm 0,07\end{array}$ & $\begin{array}{c}45,10 \mathrm{a} \pm \\
0,00\end{array}$ & 0,09 & 0,51 \\
\hline 2 & $\begin{array}{c}44,80 \mathrm{~b} \\
\pm 0,21\end{array}$ & $\begin{array}{c}44,20 \mathrm{c} \\
\pm 0,00\end{array}$ & $\begin{array}{c}45,10 \mathrm{a} \pm \\
0,00\end{array}$ & 0,09 & 0,86 \\
\hline 3 & $\begin{array}{c}44,30 \mathrm{a} \pm \\
0,21\end{array}$ & $\begin{array}{c}44,40 \mathrm{a} \\
\pm 0,07\end{array}$ & $\begin{array}{c}45,10 \mathrm{a} \pm \\
0,00\end{array}$ & 0,32 & 1,06 \\
\hline 4 & $\begin{array}{c}43,80 \mathrm{~b} \\
\pm 0,00\end{array}$ & $\begin{array}{c}44,50 \mathrm{a}, \mathrm{b} \\
\pm 0,00\end{array}$ & $\begin{array}{c}45,10 \mathrm{a} \pm \\
0,00\end{array}$ & 0,45 & 0,27 \\
\hline 5 & $\begin{array}{c}43,50 \mathrm{c} \pm \\
0,14\end{array}$ & $\begin{array}{c}44,50 \mathrm{~b} \\
\pm 0,00\end{array}$ & $\begin{array}{c}45,10 \mathrm{a} \pm \\
0,00\end{array}$ & 0,42 & 0,15 \\
\hline 6 & $\begin{array}{c}43,20 \mathrm{c} \pm \\
0,14\end{array}$ & $\begin{array}{c}44,60 \mathrm{~b} \\
\pm 0,00\end{array}$ & $\begin{array}{c}45,10 \mathrm{a} \pm \\
0,00\end{array}$ & 0,18 & 0,15 \\
\hline 7 & $\begin{array}{c}42,90 \mathrm{c} \pm \\
0,00\end{array}$ & $\begin{array}{c}44,60 \mathrm{~b} \\
\pm 0,00\end{array}$ & $\begin{array}{c}45,10 \mathrm{a} \pm \\
0,00\end{array}$ & 0,00 & 0,55 \\
\hline 8 & $\begin{array}{c}42,50 \mathrm{c} \pm \\
0,00\end{array}$ & $\begin{array}{c}44,70 \mathrm{~b} \\
\pm 0,00\end{array}$ & $\begin{array}{c}45,10 \mathrm{a} \pm \\
0,00\end{array}$ & 0,00 & 0,41 \\
\hline 12 & $\begin{array}{c}42,30 \mathrm{~b} \\
\pm 0,28\end{array}$ & $\begin{array}{c}44,70 \mathrm{a} \\
\pm 0,00\end{array}$ & $\begin{array}{c}45,10 \mathrm{a} \pm \\
0,00\end{array}$ & 0,37 & 0,78 \\
\hline 10 & $\begin{array}{c}41,90 \mathrm{c} \pm \\
0,07\end{array}$ & $\begin{array}{c}44,80 \mathrm{~b} \\
\pm 0,00\end{array}$ & $\begin{array}{c}45,10 \mathrm{a} \pm \\
0,00\end{array}$ & 0,09 & 0,63 \\
\hline 12,00 & $\begin{array}{c}44,80 \mathrm{~b} \\
\pm 0,07\end{array}$ & $\begin{array}{c}45,10 \mathrm{a} \pm \\
0,00\end{array}$ & 0,00 & 0,93 \\
\hline 0,07
\end{tabular}

* Coeficiente de variação; a,b letras iguais nas linhas significam que os tratamentos não diferiram entre si $(p>0,05)$, pelo teste de Tukey. PPc-galões de polipropileno com circulação forçada .PP - galões de polipropileno estático;

Nos meses dois, cinco a oito, dez e onze, todos os tratamentos diferiram $(p \leq 0,05)$ entre si. No mês três, nenhum dos tratamentos diferiu $(p>0,05)$ entre si. $O$ tratamento padrão no mês um diferiu $(\mathrm{p} \leq 0,05)$ do tratamento PP e, nos meses quatro, nove e doze, diferiu $(\mathrm{p} \leq 0,05)$ do tratamento PPc. Os tratamentos PPc e PP diferiram $(\mathrm{p} \leq 0,05)$ entre si nos meses um, nove e doze e não diferiram $(\mathrm{p}>0,05)$ no mês quatro. 
Alguns autores, estudando o efeito da circulação forçada da aguardente de cana-de-açúcar de cana, avaliaram doze amostras de cachaça envelhecidas durante 180 dias, em pequenos ancorotes de carvalho de cinco litros, sendo seis envelhecidas de forma tradicional e seis envelhecidas em um processo de circulação forçada, e amostra controle em galões de vidro de cinco litros. Verificou-se que, dentre as amostras envelhecidas com circulação forçada, ocorreu um aumento de $1,2 \%$ no teor alcoólico, valor este, por sua vez, menor que o observado nas amostras envelhecidas tradicionalmente $(2,8 \%)$. Os autores concluíram que o processo de circulação forçada não apresentou, tanto do ponto de vista físico-químico como sensorial, resultados que sua adoção, como forma válida para reduzir o tempo de envelhecimento da cachaça ${ }^{14}$.

A Tabela 18 contém os valores da equação de regressão, os valores do coeficiente de determinação (R2), coeficientes de variação (C.V.) e nível de significância da regressão (p) nos tratamentos $\mathrm{PP}$ e PPc durante os doze meses de envelhecimento.
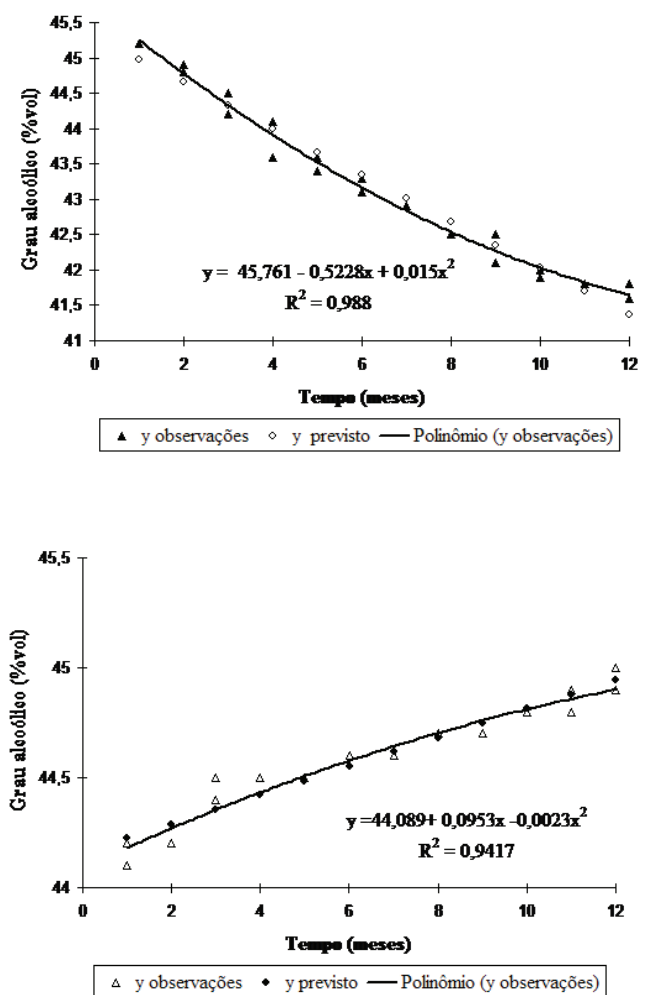

Figura 10. Evolução mensal no teor do grau alcoólico das aguardentes de cana-de-açúcar envelhecidas sob os tratamentos PPc (galões de polipropileno com circulação forçada) e PP (galões de polipropileno estático), respectivamente.

O tratamento PPc que utilizou galão de polipropileno e circulação forçada teve uma diminuição quase que constante de forma polinomial no grau alcoólico. Este obteve coeficiente de variação $(0,48)$ baixo, de acordo com Gomes (1985), indicando, então, um experimento preciso. A diminuição do grau alcoólico pode estar relacionada com a incidência da luz nas embalagens e fazendo com que ocorresse um aumento da evaporação da fração de água e etanol da aguardente de cana-deaçúcar, visto que o galão de polipropileno é resistente à umidade e impermeável ao vapor de água, porém possui baixa resistência à luz. Como foi um tratamento controle do galão de polipropileno, pode-se verificar, então, que o galão de polipropileno, com a incidência de luz, influenciou na perda de etanol nos tratamentos.
Na Figura 10, estão apresentados os gráficos da evolução mensal do grau alcoólico para os tratamentos. 
O tratamento PP em que se utilizou apenas galão de polipropileno estático teve um aumento quase que constante e de forma polinomial, tratamento este, que na disposição da sala de envelhecimento, ficava longe da incidência de luz solar. Sendo assim, o galão conseguiu manter por mais tempo a fração de etanol, não diminuindo o grau alcoólico final da bebida. Pode-se verificar, então que, desde que adequadamente armazenada, o galão plástica de polipropileno não influencia no envelhecimento da bebida.

Nestes tratamentos, pode-se verificar que o bombeamento não influencia na diminuição ou aumento do grau alcoólico.

\section{Conclusão}

Após o acompanhamento dos teores de extrato seco, acidez, densidade e grau alcoólico, da aguardente de cana-de-açúcar armazenada em diferentes madeiras, foi possível concluir que a circulação aparentemente não influenciou no envelhecimento em nenhum dos tratamentos, tendo em vista que todos os processos, utilizando aceleração forçada, aceleração forçada com cavacos, em embalagens PP, tiveram menor extração dos componentes da madeira para a bebida.

Ao final de doze meses de estudo, as análises de extrato seco e acidez indicaram que a adição de cavacos acelerou o processo de envelhecimento, já que o tratamento em barril com cavacos e circulação foi o que obteve maior concentração de extrato seco e acidez, em relação ao tratamento tradicional.

O galão de polipropileno não é apropriado para o envelhecimento da aguardente de cana-de-açúcar em nenhuma das análises realizadas, visto que comparada ao envelhecimento tradicional teve seus teores de extrato seco, acidez, densidade e grau alcoólico sempre inferiores.

\section{Referências Bibliográficas}

1. Brasil. Ministério da Agricultura, Pecuária e Abastecimento. Portaria n. 13, de 29 de junho de 2005. Aprova o regulamento técnico para fixação dos padrões de identidade e qualidade para aguardente de cana-de-açúcar de cana e para cachaça. Diário Oficial [da] República Federativa do Brasil, Brasília, DF, 30 jun. 2005. Seção 1, p.3.

2. Lima, U.A.; Aquarone, E.; Borzani, W.; Schmidell, W. Biotecnologia industrial: processos fermentativos e enzimáticos.
São Paulo: Edgard Blucher, 2001.vol.3. 593 p.

3. Novaes, F.V. Produção de aguardente de cana-de-açúcar de cana de alambique. Piracicaba: São Paulo, 2000. 67 p.

4. Expocachaça (2016) Acessado em 10/04/2016, Disponível em:$<$ http://www.expocachaca.com.br/bh/numeros-da-cachaca.shtml $>$

5. Cardello, H.M.A.B.; Faria, J.B. Análise descritiva quantitativa da aguardente de cana-de-açúcar de cana durante o envelhecimento em tonel de carvalho (Quercus alba L.). Ciênc. e Tecnol. de Aliment., Campinas, v. 18, n. 2, p.169-175, 1998.

6. Mapa. Ministério Da Agricultura, Pecuária E Abastecimento (Brasil). Manual de análises de bebidas e vinagres: destilados. Brasília: 2005. 67 p.(Manual operacional de bebidas e vinagres, caderno 5).

7. Furtado, S.M.B. Avaliação sensorial descritiva de aguardente de cana-de-açúcar de cana: influência da composição em suas características sensoriais e correlação entre as medidas sensoriais e físico-químicas. 1995. 98 f. Tese (Doutorado em Tecnologia de Alimentos) - Faculdade de Engenharia de Alimentos, Universidade Estadual de Campinas, Campinas, 1995.

8. Forlin, F.J. Maturação de aguardente de cana-de-açúcar de cana composta com extrato de madeira de carvalho em embalagens de polietileno tereftalato (PET). 2005. 176 f. Tese (Doutorado em Tecnologia de Alimentos) - Faculdade de Engenharia de Alimentos, Universidade Estadual de Campinas, Campinas, 2005.

9. Castro Neto, J.T. Envelhecimento de aguardente de cana-deaçúcar de cana com circulação forçada: efeito da presença de ar no sistema. 2004. 56f. Dissertação (Mestrado em Ciência dos Alimentos) - Faculdade de Ciências Farmacêuticas, Universidade Estadual Paulista, Araraquara, 2004.

10. Castro Neto, J.T.; Borragini, M.C.C.; Faria, J.B. Efeito da presença de ar no envelhecimento de aguardente de cana-deaçúcar de cana com circulação forçada. Alim. e Nutr., Araraquara, v. 16, n.3, p.239-243, 2005.

11. Queiroz, E.L.M.T. Envelhecimento forçado da aguardente de cana-de-açúcar de cana: estudo comparativo com o envelhecimento tradicional em carvalho (Quercus sp). 1998. 82 f. Dissertação (Mestrado em Alimentos e Nutrição) - Faculdade de Ciências Farmacêuticas, Universidade Estadual Paulista, Araraquara, 1998.

12. Tavares, J.R.P.; Nascimento, R.F.; Neves, M.F.S.; Vargas, M.E.S.; Silva, F.O.; Rosa, P.C.R. Cachaças comerciais envelhecidas e sem envelhecer: um perfil quantitativo do grau alcoólico e dos teores de cobre e de açúcares. Rev. Bras. de Farm., Rio de Janeiro, v. 84, n. 3, p. 87-90, 2004.

13. Souza, M.D.C.A.; Del Castro, N.L. Efeito da radiação gama na aguardente de cana-de-açúcar de cana-de açúcar. Braz. J. Food Technol., Campinas, v. 7, n. 1, p. 9-15, 2004.

14. Padovan, F.C.; Borragini, M.C.C.; Faria, J.B. Efeito da circulação da aguardente de cana-de-açúcar de cana no tempo de envelhecimento em ancorotes de carvalho (Quercus sp). Alim. e Nutr., Araraquara, v. 15, n.3, p.267-271, 2004. 


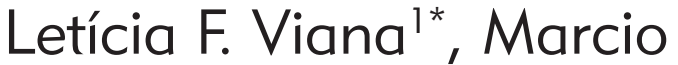 Caliari' $^{2}$, Manoel S. S. Junior ${ }^{2}$ \& Paulo R. L. V. Filho ${ }^{3}$}

${ }^{1}$ Instituto Federal Goiano, Departamento de Alimentos, Campus Rio Verde, Goiás, Brasil.

${ }^{2}$ Universidade Federal de Goiás, Escola de Agronomia e Engenharia de Alimentos, Goiânia, Goiás, Brasil.

${ }^{3}$ Agrodefesa, Goiânia, Goiás, Brasil.

*E-mail:1fleuryviana@gmail.com 